\title{
First Demonstration of Radiative Power Exhaust with Impurity Seeding in the Island Divertor at Wendelstein 7-X
}

\author{
F. Effenberga,*, S. Brezinsek ${ }^{\mathrm{c}}$, Y. Feng ${ }^{\mathrm{b}}$, R. König ${ }^{\mathrm{b}}$, M. Krychowiak $^{\mathrm{b}}$, M. Jakubowski $^{\mathrm{b}}$, H. Niemann $^{\mathrm{b}}$, V. Perseo ${ }^{\mathrm{b}}$, O. \\ Schmitz $^{\mathrm{a}}$, D. Zhang ${ }^{\mathrm{b}}$, T. Barbui ${ }^{\mathrm{a}}$, C. Biedermann ${ }^{\mathrm{b}}$, R. Burhenn ${ }^{\mathrm{b}}$, B. Buttenschön ${ }^{\mathrm{b}}$, G. Kocsis ${ }^{\mathrm{d}}$, A. Pavone ${ }^{\mathrm{b}}$, F. \\ Reimold $^{\mathrm{b}}$, T. Szepesi ${ }^{\mathrm{d}}$, H. Frerichs ${ }^{\mathrm{a}}$, Y. Gao ${ }^{\mathrm{c}}$, U. Hergenhahn $^{\mathrm{b}}$, S. Kwak ${ }^{\mathrm{b}, \mathrm{e}}$, M. Otte ${ }^{\mathrm{b}}$, T. Sunn Pedersen $^{\mathrm{b}}$, W7-X Team $^{\mathrm{b}}$

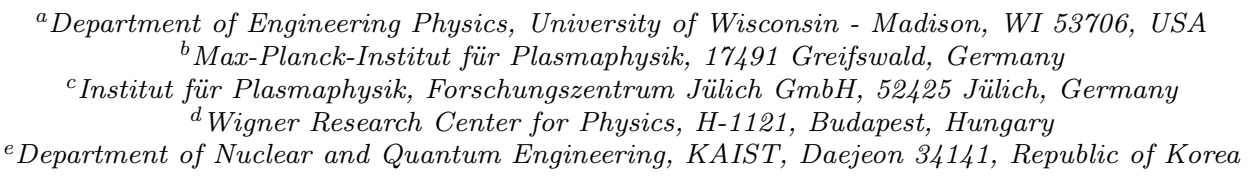

\begin{abstract}
Radiative power exhaust by impurity seeding was demonstrated for the first time in island divertor configurations at the stellarator Wendelstein 7-X. Feasibility of stable plasma operation was shown during seeding with both neon $(\mathrm{Ne})$ and nitrogen $\left(\mathrm{N}_{2}\right)$. High radiative power losses $(\geq 80 \%)$ were found to reduce the divertor heat loads globally by $2 / 3$ with both seeding gases injected at a single toroidal location into one of five magnetic islands. Heat flux detachment was achieved for the price of a loss of $(\geq-15 \%)$ in the stored energy. Ne seeding allows for sustained enhancement of edge radiation with a very slow decay of line emission of several tens of seconds after the end of the injection indicating a high recycling of this noble gas at the carbon main plasma facing components. In $\mathrm{N}_{2}$ seeded discharges it is shown that a response of line emission and plasma parameters is in correlation to the puff duration which indicates a higher level of absorption of this seeding gas in the wall. Continuous $\mathrm{N}_{2}$ seeding results in global cooling of the scrape-off layer (SOL) and decay of radiation over several seconds after the injection. Damping of counter-streaming SOL flows, and divertor particle fluxes induced by $\mathrm{Ne}$ and $\mathrm{N}_{2}$ seeding have been measured and provide evidence for a reduction of the convective part of the divertor heat fluxes. Losses in density in response to seeding can be compensated by feedback controlled divertor fueling. The controlled reduction of heat fluxes within this complex 3D edge island geometry is a very promising finding concerning detachment control in a future all-metal divertor.
\end{abstract}

Keywords: stellarator, scrape-off layer, island divertor, power exhaust, impurity seeding, detachment

\section{Introduction}

2 Excessive heat and particle loads onto main plasma fac- ${ }^{20}$ ing components (PFCs) are a major concern on the way to-

4 wards a nuclear fusion demonstration power plant. Tokamaks and stellarators are currently the leading concepts 6 in magnetically confined fusion. Experiments such as the Joint European Torus (JET), the Large Helical Device 8 (LHD) and Wendelstein 7-X (W7-X) are currently the largest devices of these types to tackle the reactor relevant heat and particle exhaust issue via different divertor concepts $1,2,3$.

12 The parallel heat fluxes $q_{\|}$within the scrape-off layer (SOL) are determined by the input power entering the

${ }_{14}$ SOL and the heat flux fall-off length $\lambda_{q}$ [4. Controlling ${ }_{32}$ this heat flux will become crucial for the stellarator W7-X which operates inherently steady state and presently as- 34 pires to long pulse high-performance operation to demon-
*Corresponding author
Email address: effenberg@wisc.edu (F. Effenberg) technically feasible target heat flux limits are $q_{d i v, \max } \approx$ determined by the magnetic field line connection lengths $L_{C}$. In a stellarator, and in particular in the island divertor of W7-X, these connection lengths are generally $L_{C, W 7 X} \propto O(100 \mathrm{~m})$ and are predicted to scale up in a reactor to $\left(L_{C, W 7 \text {-reactor }} \propto O(1000 \mathrm{~m})\right.$ 8, 9]. Therefore, perpendicular difusion of particles and heat is more effective and a broader heat flux deposition width is expected. However, even with this mitigating topological advantage, excessive heat fluxes are also expected for highperformance stellarator plasmas [10, [11, 12.

To avoid damage of the PFCs and material erosion due to excessive heat fluxes and high target temperature additional means to control and mitigate the heat flux issue are under investigation. Radiative edge cooling is a promising approach to remove most of the thermal power coming from the main plasma confinement before it reaches the plasma facing components [13, 14, 15, 16]. Here, dedicated 3 low and medium atomic charge impurity species are used to dissipate significant amounts of the power entering the 
SOL by impurity line emission. This power loss channel allows in principle for active control and modification of the energy balance through the amount of impurities released into the plasma. For steady state, long pulse operation it is even more desired to use the impurity line radiation to cool the plasma edge such that the temperatures downstream near the main PFCs are reduced and reliably controlled at levels of a few eV or less. The wall material and sputtering physics determine the intrinsic line radiation. W7-X uses carbon as first-wall material, which has the advantage of some level of self-protection due to line emission of eroded carbon featuring the strongest radiation at typical SOL temperatures. However, the first-wall of future devices such as ITER and DEMO will have to use higher $Z$ materials such as tungsten in order to reduce tritium retention and maintain the wall integrity without massive erosion [17, 18, 19]. Here, the advantageous intrinsic power loss channels through carbon line emission are no longer available, and other extrinsic impurities have to replace these intrinsic edge radiators 20. This issue will have to be investigated in the complex $3 \mathrm{D}$ geometry of $\mathrm{W} 7-\mathrm{X}$ in preparation for next-step stellarators devices [21, 22].

In this study, a first-time assessment of dedicated impurity seeding experiments for radiative power exhaust in the island divertor configuration is undertaken.

Understanding the essential features of transport and exhaust of heat and particles requires in the present study $3 \mathrm{D}$ modeling due to the inherent complex 3D magnetic SOL geometry of the W7-X stellarator. For this purpose the experimental results will be compared with modeling results obtained from the $3 \mathrm{D}$ plasma edge fluid and kinetic neutral transport Monte Carlo code EMC3-EIRENE [23. 24.

The heat fluxes and impurity transport within the scrape-off layer (SOL) of inherently 3D devices have been 98 studied with 3D modeling, e.g. at LHD [25, 26, 27, at HSX 28, 29, HIDRA [30], at W7-AS [31, and W7 $7_{\text {×о }}$ $\mathrm{X}$ 9, 32, 33, 34, 12.

First characterizations of the heat fluxes and imputo2 rity transport in the $\mathrm{W} 7-\mathrm{X}$ limiter configuration showed a strong dependence of the transport and plasma-surface 04 interactions (PSI) on the 3D helical connection lengths topology $\left(L_{C} \approx O(10 \mathrm{~m})\right)$ 34. The effects of the 3D geometry on limiter heat fluxes were resolved by both, 3D modeling and experimental measurements 34, 35. Changes to ${ }^{\circ 6}$ the magnetic geometry showed the feasibility of heat and particle load control [35, 36, and optimization of particle exhaust 37] in this 3D configuration.

W7-X was operated in summer to fall 2017 and 2018 in island divertor configurations for the first time. In this10 configuration the lengths $L_{C}$ of the open field lines are increased by a factor of 10 in comparison to the limiter 12 SOL during the W7-X startup campaign. A first analysis of divertor heat fluxes and promising results with regard 14 to stable and high density operation were reported in 38 . A first comparison of the impact of the island geometry on 16 divertor heat fluxes between experiment and 3D modeling

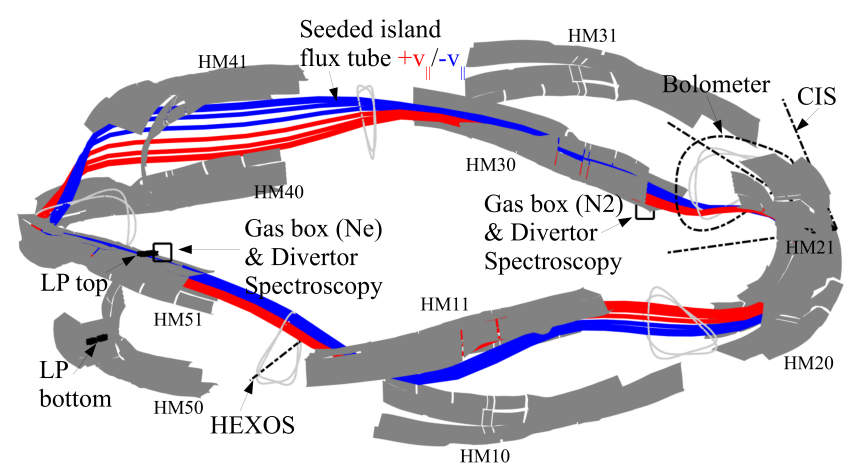

Figure 1: The geometry of the standard island divertor configuration. Full toroidal view on divertor modules and an open field line (red and blue) traced within the seeded island. Red and blue indicate the flow directions of main plasma and impurity ions.
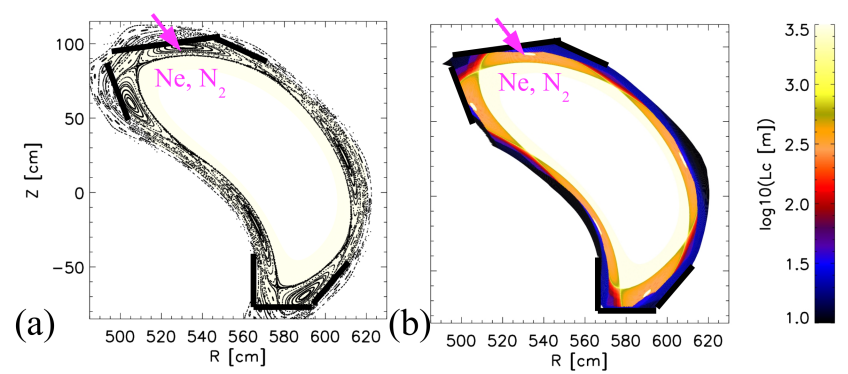

Figure 2: The geometry of the standard island divertor configuration. (a) Poincare plot of the vacuum boundary magnetic field (standard divertor configuration). (b) Target-to-target connection lengths $L_{C}$.

was reported in 39 .

In section 2 the properties of the island divertor configuration and the seeding scenarios considered will be introduced. The models used for the analysis in this work are introduced in section 3 . The main effects of $\mathrm{Ne}$ and $\mathrm{N}_{2}$ seeding on heat and particle fluxes are analyzed in sections 4 and 5 . A final discussion and conclusions are provided in the sections 6 and 7 .

\section{Impurity seeding in the standard island divertor configuration}

Challenge imposed by the island divertor exhaust geometry. The experiments performed here were conducted in the $\iota=5 / 5$ standard island divertor configuration [40. Five helical island bands enclose the core confinement domain. Ten carbon divertor units represent the main plasma facing components. A view on the geometry of this configuration and its main plasma facing components is provided in figure 1 .

The lower and upper divertor modules are labeled as $\mathrm{HM} X 0$ and $\mathrm{HM} X 1$, respectively, with $X=1-5$. An open magnetic field line is traced within one of the five magnetic 
islands corresponding to a single target-to-target connection length of $L_{C} \approx 460 \mathrm{~m}$ (corresponds to approximately 13 toroidal turns). The field line is traced from the upstream position at the separatrix in positive (red) and neg ${ }^{176}$ ative (blue) toroidal direction until it hits a divertor target (downstream). The colors represent the counter-streaming flow directions discussed later in this study. The island flux bundle is connected to the upper and lower divertor gas boxes used for $\mathrm{Ne}$ and $\mathrm{N}_{2}$ seeding and diagnostic purposes [41, 42 (HM51:Ne and HM30: $\mathrm{N}_{2}$ ). Langmuir probe arrays are mounted near the gas box (Ne) in the top divertor (HM51) and on the bottom divertor (HM50) which is not connected to the seeded island 43. The Bolometer provides the total radiated power derived from two nearly orthogonal cameras covering a poloidal cross section in the triangular plane next to the divertor in the same module with the bottom gas box (HM30, $\left.\mathrm{N}_{2}\right)$ 44]. The seeded island crosses the bolometer observation plane at the bottom. Divertor heat fluxes are measured by IR cameras 45, 46. A coherence imaging spectroscopy (CIS) with a toroidal view is used to measure impurity ion flow velocities 47, 48, 49. The impurity line emission is measured at the mid plane with the high-efficiency extreme ultraviolet overview spectrometer (HEXOS) 50. The setup of the neutral pressure gauges is described in [51. An overview of the diagnostic setup is also provided in $[52$.

A Poincare plot of the boundary vacuum magnetic field is shown in figure 2(a). The islands are intersected by divertor plates (back solid lines). The cross section represents the toroidal cross section with a divertor gas box. The open field line domain is shown in figure $2(\mathrm{~b})$. The target-to-target connection lengths $L_{C}$ vary between $O(1$ $\mathrm{km})$ at the separatrix, $O(100 \mathrm{~m})$ within the islands and $O(1 \mathrm{~m})-O(10 \mathrm{~m})$ in the far SOL and private flux region.

The seeded impurities are released into the island center or island $O$-point. The solid black lines indicate the ${ }^{90}$ divertor targets and baffles on this poloidal plane. The gap between the top center and top left plate is the pumpt92 ing gap used for the neutral exhaust. The plates on the bottom belong to a bottom divertor.

In view of the fact that the five islands of the standard divertor configuration are magnetically isolated from 96 each other, a question emerges immediately as whether it is possible to perform homogeneous radiation cooling byis seeding. It is not anticipated that this geometry and use of a single gas source will allow for homogenous mitigationoo of the heat and particle loads on all divertor targets. This question will be addressed in the following analysis of theo2 cooling effects induced by neon and nitrogen seeding.

The choice of impurities is made based on experimental experiences from different devices and the first limiter operational phase [13, 53, 54?] The cooling potentials of $\mathrm{C}$ and $\mathrm{N}_{2}$ are similar and provide for strongest radiation at low temperatures. Neon generally radiates at higher temperatures and may cause radiative losses closer to the upstream location. The experiments discussed in the following will consider the impact on energy confinement in case of high radiation losses 53 .

\section{3D modeling of plasma transport and plasma- surface interactions}

The main plasma transport. EMC3-EIRENE is a fully 3D coupled plasma fluid and kinetic edge transport Monte Carlo code. EMC3 solves a set of reduced Braginskii fluid equations for particles, parallel momentum, and energies for electrons and ions [23, 56. EIRENE solves the kinetic transport equations for neutral atoms and molecules including collisional processes 24, 57. The Braginskii fluid equations for mass, momentum, and energy for electrons and ions are:

$$
\begin{array}{r}
\nabla_{\|} \cdot\left(n V_{\|}\right)+\nabla_{\perp} \cdot\left(-D_{\perp} \nabla_{\perp} n\right)=S_{P} \\
\nabla_{\|} \cdot\left(m_{i} n V_{\|} V_{\|}-\eta_{\|} \nabla_{\|} V_{\|}\right) \\
+\nabla_{\perp} \cdot\left(-m_{i} V_{\|} D_{\perp} \nabla_{\perp} n-\eta_{\perp} \nabla_{\perp} V_{\|}\right)= \\
-\nabla_{\|} n\left(T_{e}+T_{i}\right)+S_{m} \\
+\nabla_{\perp} \cdot\left(-\chi_{\perp}^{e} n \nabla_{\perp} T_{e}-\frac{5}{2} T_{e} D_{\perp} \nabla_{\perp} n\right)= \\
-k\left(T_{e}-T_{i}\right)+S_{e e}+S_{e, i m p} \\
\nabla_{\|} \cdot\left(-\kappa_{\|}^{e} \nabla_{\|} T_{e}+\frac{5}{2} n T_{e} V_{\|}\right) \\
\nabla_{\|} \cdot\left(-\kappa_{\|}^{i} \nabla_{\|} T_{i}+\frac{5}{2} n T_{i} V_{\|}\right) \\
5 \\
+\nabla_{\perp} \cdot\left(-\chi_{\perp}^{i} n \nabla_{\perp} T_{i}-\frac{5}{2} T_{i} D_{\perp} \nabla_{\perp} n\right)= \\
-k\left(T_{e}-T_{i}\right)+S_{e i}
\end{array}
$$

where $V_{\|}, \kappa_{\|}^{e, i}$ and $k$ are the parallel plasma velocity, the classical parallel electron/ion heat conductivity, and the equilibration coefficient. $S_{p}, S_{m}, S_{e e}$ and $S_{e i}$ are the particle, momentum and energy sources associated with atomic and molecular processes, e.g., charge exchange (CX) and ionization, which are calculated by EIRENE.

$S_{e, i m p}$ represents an energy loss term due to excitation and ionization of impurities described in a fluid approach within EMC3. The coefficients for anomalous particle transport $D_{\perp}$ and anomalous electron and ion heat transport $\chi_{\perp, e, i}$ are free model parameters. Edge plasma heating is defined by setting the electron and ion heating power across the inner simulation boundary.

Impurity sources and SOL impurity transport. Release of intrinsic and extrinsic impurities is modeled based on a simplified approach by setting an effective sputtering yield $Y_{\text {sputter }}$ to mimic recycling or chemical sputtering of impurities. The impurity fluxes are then proportional to the strengths and distributions of the local recycling fluxes $\Gamma_{r e c}$ :

$$
\Gamma_{i m p} \approx \Gamma_{i m p}=Y_{\text {sputter }} \Gamma_{r e c}
$$


A point source can be defined with a impurity flow rate in

order to start the impurities at the seeding location. For seeded impurities the total power loss $P_{r a d}$ are used as a free parameter in this study and the impurity fluxes are code outputs.

Once the neutral impurities are released and ionized their transport is modeled by a trace fluid approach. A simplified fluid momentum balance equation is solved and the impurities impact the main plasma species only by ionization and excitation through a loss term in the energy balance equation. The following continuity and momentum equations are solved:

$$
\begin{gathered}
\nabla_{\|} \cdot\left(n_{z} V_{z \|}\right)+\nabla_{\perp} \cdot\left(-D_{i m p} \nabla_{\perp} n_{z}\right)=S_{z} \\
0=-\frac{1}{n_{z}} \frac{d p_{z}}{d s}+Z e E_{\|}+m_{z} \frac{V_{\|}-V_{z \|}}{\tau_{z i}} \\
\quad+0.71 Z^{2} \frac{d T_{e}}{d s}+2.6 Z^{2} \frac{d T_{i}}{d s} \\
=F_{P}+F_{E}+F_{f r}+F_{t h, e}+F_{t h, i}
\end{gathered}
$$

where $S_{z}$ represents the impurity ionization source for charge state $Z$, and $D_{i m p}$ is the anomalous particle diffusivity. $\tau_{z i}$ is the collision time between impurities and background main ions 4]:

$$
\tau_{z i}=\frac{1.47 \cdot 10^{13} m_{z}\left(T_{i}^{3} / m_{i}\right)^{0.5}}{\left(1+m_{i} / m_{z}\right) n_{i} Z^{2} \ln \Lambda}
$$

with $\ln \Lambda \approx 15$. The terms in equation 8 correspond to pressure force $F_{P}$, electric force $F_{E}$, friction force $F_{f r}$ and electron and ion thermal force $F_{t h, e}$ and $F_{t h, i}$, respectively. The impurity ion temperatures are assumed to be equal to the background main ion temperature $\left(T_{z}=T_{i}\right)$.

The fluid approach is chosen for the first-step analysis in this study. Here, the focus is on general transport features of the impurity transport within the fluid picture. The ADAS database 58 provides the atomic data, namely effective rate coefficients for ionization, recombination and charge exchange and relevant line emission.

Assumptions. The standard island divertor configura ${ }^{252}$ tion was implemented in EMC3-EIRENE to assess the main features of radiative power exhaust by extrinsic im $^{254}$ purities on plasma transport and plasma surface interactions for the typical plasma conditions realized. The heat and particle transport is considered for a scenario with $a_{256}$ input power of $P=4.0 \mathrm{MW}$ and an upstream density of $n_{u p}=2.0 \cdot 10^{19} \mathrm{~m}^{-3}$ fixed at the separatrix which was obtained based on measurements with the helium beam58 diagnostic and Thomson scattering. $D_{\perp}=\chi_{\perp, e, i}=1.0$ $\mathrm{m}^{2} \mathrm{~s}^{-1}$ were assumed to achieve modeling results for the heat fluxes which are in a satisfying agreement. A sputtering yield of $Y_{\text {sputter }}=0.04$ is used for carbon based62 on an estimation of the total intrinsic power losses and the assumption that $\mathrm{C}$ is the dominant intrinsic impurityes source. The carbon is also used as a probe for a synthetic coherent imaging spectroscopy diagnostic in the following 66
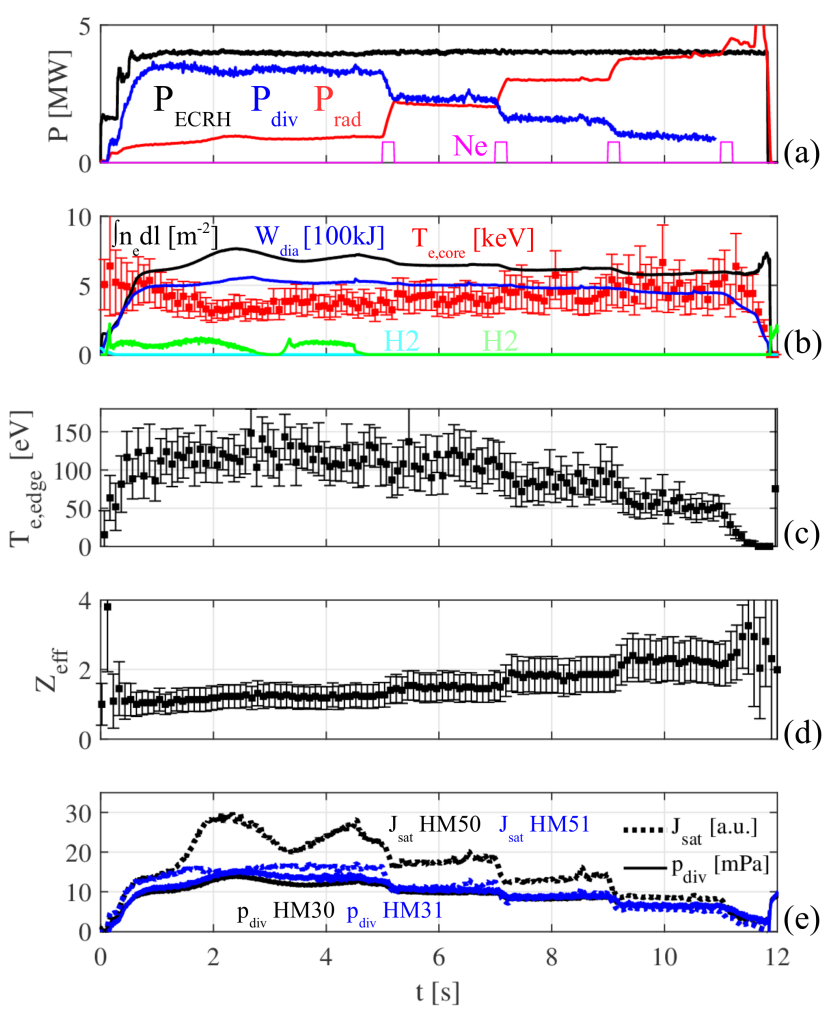

Figure 3: Time evolution of the scenario with Ne seeding (\#20180920.042). (a) injected heating power (black) radiated power (red), power deposited on divertor (blue), Ne seeding rate from gas box in HM51 (magenta) (b) line integrated density (black), plasma stored energy $W_{d i a}$ (blue), core electron temperature $T_{e, c o r e}$ (red) from Thomson scattering (V8) near axis, $\mathrm{H}_{2}$ fueling rates from main gas inlets (green and cyan), (c) Thomson scattering edge temperature (V8), (d) average effective charge state $Z_{\text {eff }}$, (e) neutral pressure (AEH-ports in HM30 and HM31) and local particle fluxes ( $J_{\text {sat }}$ in HM50 and HM51) at lower and upper divertor.

[59. Neon and nitrogen are released into the SOL according to their main source locations. Stellarator-symmetry is used to reduce computational effort for this primary qualitative assessment. A $P_{\text {rad }}$ scan has been performed with respect to the extrinsic radiators to mimic the systematic enhancement of edge radiation by impurity seeding. This allows to investigate the impact on SOL parameters and PWI within the modeling.

\section{Effects of Ne seeding}

A representative hydrogen plasma scenario with neon seeding is discussed in the following (experiment ID \#20180920.042). The time evolution of the main plasma parameters is shown in figure 3 A constant electroncyclotron-resonance heating $(\mathrm{ECRH})$ power of $P_{E C R H}=$ 4.0 MW in $X 2$-mode was applied as shown in figure 3(a) (black curve). The total radiated power $P_{\text {rad }}$ was measured with the bolometer and is shown in figure (3) (a) (red curve). The total heat flux $P_{d i v}=\Sigma_{j} \int q_{d i v, j} d A_{j}$ to all divertors (blue curve) is based on IR measurements. The 
neon seeding rate is shown in magenta. Neon pulses were

injected at $t=5,7,9$ and $11 \mathrm{~s}$ with a duration of 200 ms each at a flow rate of $\Gamma_{N e} \approx 10^{20} \mathrm{~s}^{-1}$ in the upper divertor gas box (M51). The scenario was terminated by radiative collapse after the fourth Ne injection when $P_{\text {rad }}$ approached $P_{E C R H}$. The line integrated plasma density was set to $\int n_{e} d l \approx 7 \cdot 10^{19} \mathrm{~m}^{-2}$ and is depicted in figure (3) (b) (black curve) together with the plasma stored energy $W_{d i a}$ (blue curve) and the core electron temperature $T_{e, c o r e}$ (red curve) obtained from Thomson scattering (V8). The density in this scenario was chosen based on previous reference discharges, showing that wall recycling alone is sufficient to sustain an almost constant density level without the need for additional gas fueling. The feedback control of the primary gas injection system had to be set to a reduced density level after $t \approx 4.5 \mathrm{~s}$ in order to avoid perturbative hydrogen puffs covering the effects of Ne seeding. Without this measure taken impurity seeding induced density changes had always resulted in feedback system induced, unwanted hydrogen fuelling puffs. The edge electron temperature near the LCFS $T_{e, e d g e}$ obtained from Thomson scattering (V8) is shown in figure 3(c). The initial temperature is about $120 \mathrm{eV}$. The first Ne injection at $5 \mathrm{~s}$ shows no clear effect. The second Ne injection at $7 \mathrm{~s}$ causes a drop to $75-80 \mathrm{eV}$, and the third injection reduces the temperature to $50 \mathrm{eV}$. This suggests that the cooling initially happened deeper in the SOL while the radiation ${ }_{26}$ zone tends to move further inwards with increasing intensity. The effects on SOL parameters within the island are $e_{28}$ better resolved by measurements with the Helium beam diagnostic. The time evolution of electron densities and ${ }_{30}$ temperatures within the island in the bottom divertor region (HM30) are shown in figure 4(a) and (b). The values represent a range of $1-2.5 \mathrm{~cm}$ above the horizonta ${ }_{32}$ divertor plate in the island center. The density is initially $n_{e} \approx 2-3 \cdot 10^{19} \mathrm{~m}^{-3}$ and decreases after three Ne injections 34 to $1-2 \cdot 10^{19} \mathrm{~m}^{-3}$, while the electron temperature drops from $T_{e} \approx 24 \mathrm{eV}$ to $12 \mathrm{eV}$. The $\mathrm{SOL}$ parameters show a 36 stepwise response in correlation with the seeding scheme. The channels further upstream are neglected due to strongss scattering of the data. The absolute uncertainties of the temperature and density derived from a collisional radias4o tive model are affected by the atomic data accuracy. A gross systematic uncertainty across the relevant parameteв 42 range of $10-30 \%$ is expected. However, this is a systematic uncertainty which does not affect relative measurementş44 which are considered here. Therefore, only actual measurement uncertainties in the spectroscopic measurements 46 for this diagnostic are displayed.

The $Z_{\text {eff }}$ is shown in figure 3(d). It rises during the ${ }_{48}$ Ne injection from 1.2 to 2.2 . This corresponds to maximum Ne concentration (after the last puff) in the core of 50 $c_{N e} \approx 1.3 \%$. This can be related to a worst-case concentration of $c_{N e} \approx 5 \%$ if all injected Ne particles would accumus52 late in the confinement region. The lower value obtained from $Z_{\text {eff }}$ suggests that $75 \%$ of injected Ne particles ares4 retained in the SOL.
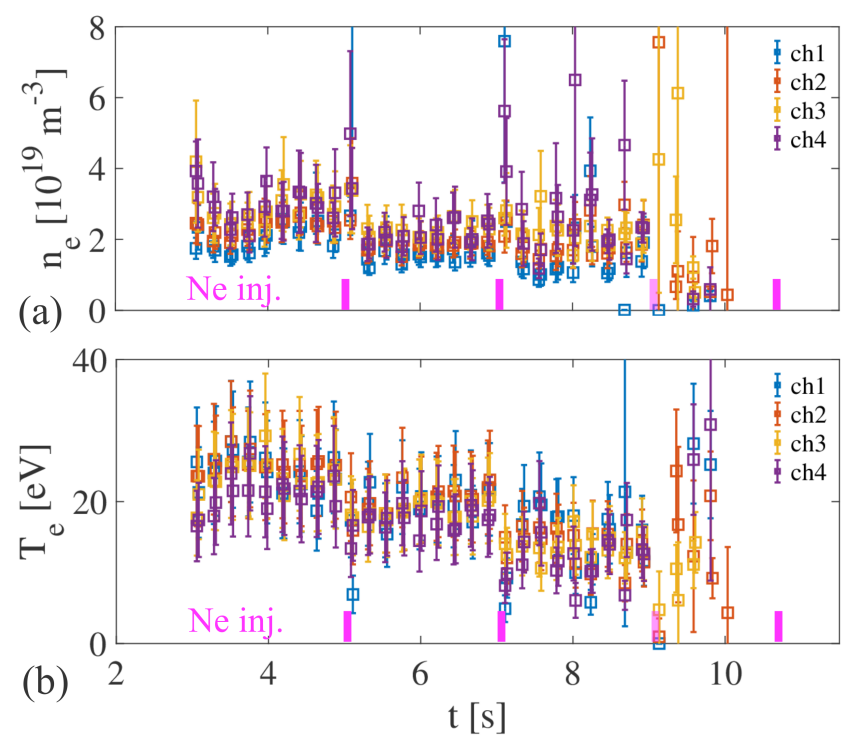

Figure 4: Time evolution of (a) electron density $n_{e}$ and (b) electron temperature $T_{e}$ measured with the Helium beam diagnostic in the outermost four channels (distance to horizontal target $d \approx 1-2.5 \mathrm{~cm}$ ) in HM30.

The total ion saturation currents were calculated as the sum $J_{\text {sat }}=\Sigma j_{\text {sat }, i}$ of the individual currents $j_{\text {sat }, i}$ from each divertor Langmuir probe. The evolution of the total currents of the two Langmuir probe arrays are shown as a proxy for the particle fluxes in figure $3(3$ (e) for lower (black) and upper divertor (blue). The sub-divertor neutral pressures (AEH ports) are shown in figure (3(e) for lower (black, HM30) and upper divertor (blue, HM31).

Analysis of the $3 D$ radiation distribution. It was demonstrated that the total radiated power, measured with the bolometer, can be reliably controlled with $\mathrm{Ne}$ seeding. The total radiative power losses consist of a base level (consider $P_{\text {rad }}$ for $t \leq 5 \mathrm{~s}$ in figure (3(a)) which is assumed to be mostly caused by line emission from intrinsic $C$ impurities. A detailed quantitative analysis of the composition of the intrinsic impurity content is still pending, but the fact that the main PFCs and shielding consisted of carbon and first measurements for the divertor campaign support this assumption [60, 61.

For simplicity consider the injected power $P_{E C R H}$ as a reference scale for the power loss discussion in the following (left axis in figure 3(a)). In response to the first Ne injection at $t=5 \mathrm{~s}$ the radiated power enhances by $\Delta P_{\text {rad }} \approx$ $1.0 \mathrm{MW}$ to $P_{\mathrm{rad}} \approx 1.8 \mathrm{MW}$. The increase in radiation almost remains constant over $2 \mathrm{~s}$ until the next injection. Each injection increases $P_{\text {rad }}$ stepwise. Moreover, $P_{\text {rad }}$ remains constant on the enhanced level during the seeding cycles. It was demonstrated in various scenarios that $P_{\text {rad }}$ enhanced by Ne decays only very slowly over at least several tens of seconds. This indicates that neon features a relatively high recycling coefficient and will remain in the plasma for a longer time. Three Ne pulses have enhanced 
the total radiated power by $\Delta P_{\text {rad }} \approx 2.5 \mathrm{MW}$. After the fourth injection, the radiated power fraction approaches the level of injected power, and a radiative collapse terminates the plasma. The radiative limit was exceeded after the release of $N_{N e} \approx 8 \cdot 10^{19}$ Ne particles into the plasma. It is a promising result that the divertor configuration allows for stable operation at high radiation losses.

The total power loss fraction can be constrained by the power deposited on the divertor and the estimation from the bolometer. After three Ne injections one may have achieved: $1-\frac{P_{\text {div }}}{P_{E C R H, i n j .}} \approx 70 \% \leq f_{\text {rad }} \leq$ $f_{\text {rad,bolometer }} \approx 95 \%$. The bolometer has an error bar of $\Delta f_{\text {rad }} \approx \pm 10 \%$. One question concerning the 3D magnetic field geometry is how the general radiation features are composed in spatial terms. This will be considered in the following.

The spatial distribution of the total radiated power is shown in figure 5(a) for the horizontal bolometer camera. This camera measures at the triangular cross-section and is due to its nearly up/down-symmetric view around the midplane best suited to resolve radiation asymmetries between the top and bottom plasma edge (see also set up in figure 1 and sketch of lines of sight in $8(a)$ ) 61]. The seeded island flux tubes pass the bolometer observation at the bottom.

First, there is a moderate intrinsic asymmetry between the top and bottom radiation which may be correlated with the higher particle fluxes measured in the bottom divertor. Higher fluxes to the neighboring bottom divertors may result in enhanced radiation in the bottom island due to higher sputtering and recycling of impurities compared to the upper divertors. This may also result in a stronger erosion and higher impurity fluxes into the island connected with the bottom divertor gas box (HM30) and which passes through the bottom of the bolometer observation plane (figure 1). The sequence of Ne injections starting at $5 \mathrm{~s}$ enhances the edge radiation at the top as well as at the bottom. The radiation is stronger at the bottom which is assumed to be in correlation with the asymmetries mentioned above of the poloidal intrinsic radiation distribution. The radiating layer expands deeper into the confinement after each injection. The radiation zone reaches the plasma center after the fourth neon injection and eventually results in a radiation collapse.

The analysis of the composition and the 3D distribution of radiation intensity is a non-trivial task in this complex 3D island SOL geometry. A first assessment is performed in the following considering the primary extrinsic and intrinsic impurity sources. Divertor spectroscopy 62 allows a view on the carbon line emission in the divertor during neon seeding. The observation is across the divertor target at the neon injection location (HM51). The LCFS is located about $9-10 \mathrm{~cm}$ above the divertor target. The time evolutions of CIII (465 nm) is shown in figure 5 (b). They represent the line emission integrated along the lines of sight at different perpendicular distances above the hor-
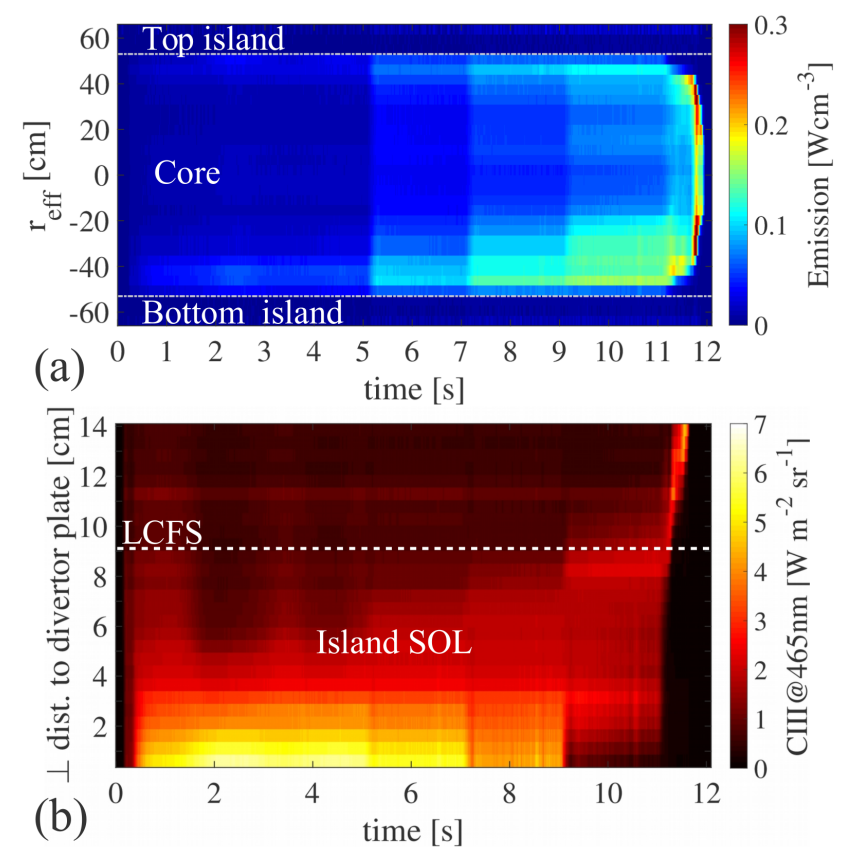

Figure 5: (a) Time evolution and vertical distribution of chordbrightness (composing the total radiated power $P_{\text {rad }}$ ) measured with the horizontal bolometer camera. (b) Carbon line emission in the HM51 divertor spectroscopy: CIII (465 nm).

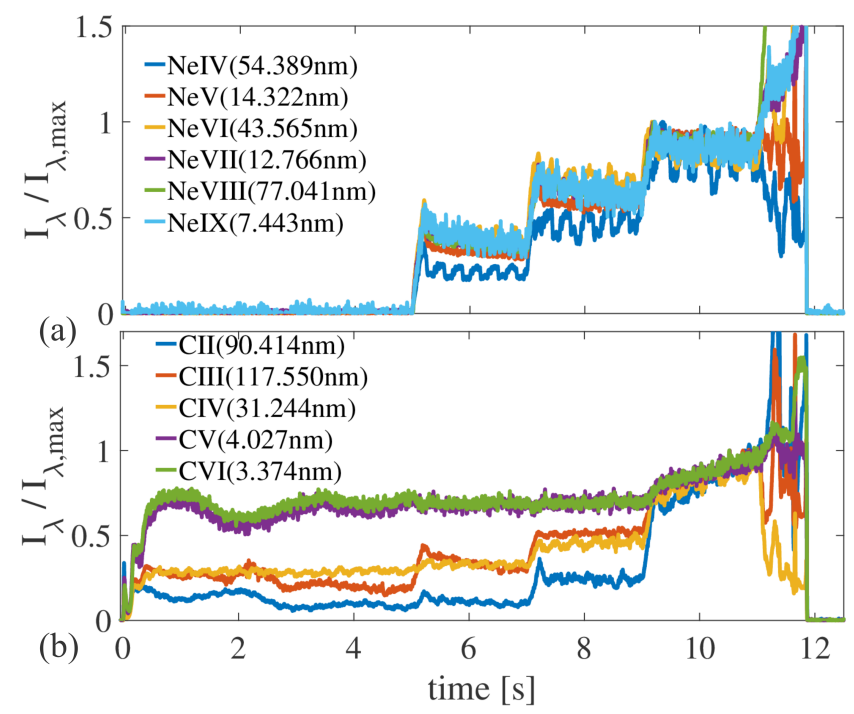

Figure 6: High efficiency XUV Overview Spectrometer (HEXOS)lines for (a) neon and (b) carbon. The line emission is measured at the mid plane $(Z=0)$ in the triangular symmetry plane. 

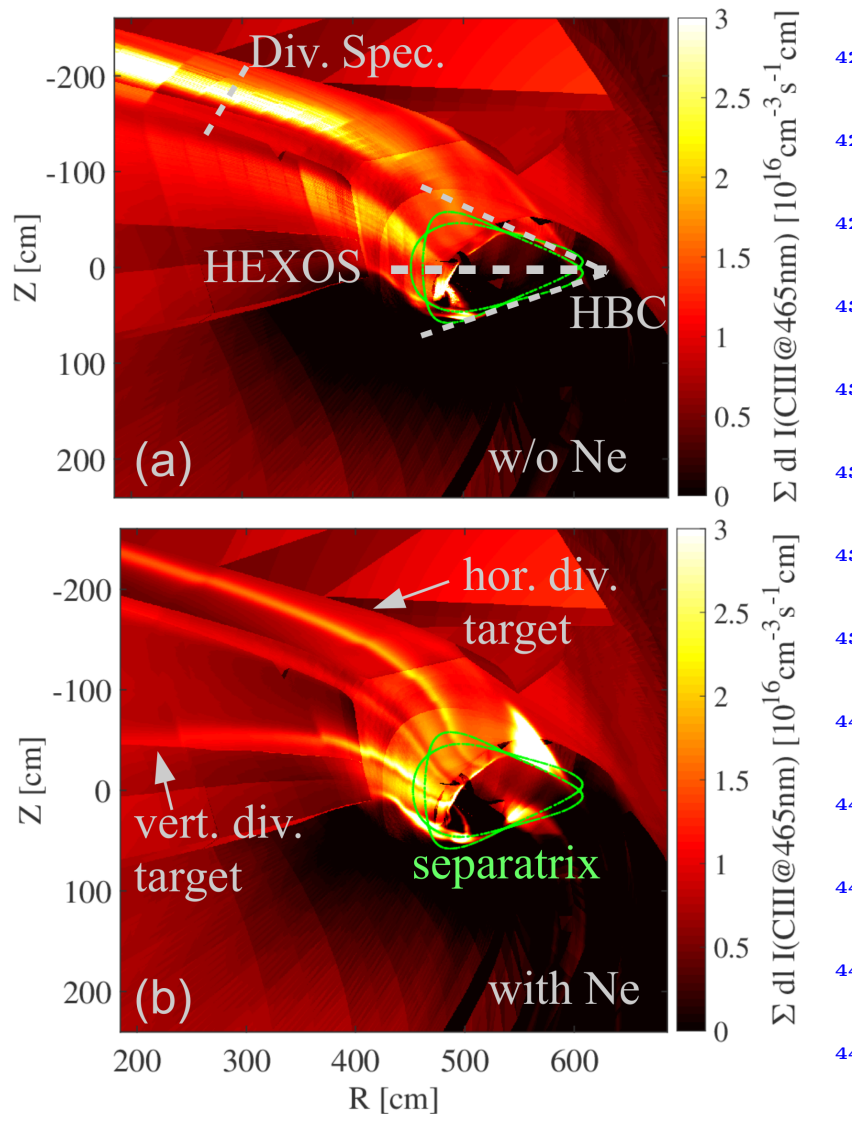

Figure 7: 3D modeling distribution of intrinsic radiation (CIII) for (a) a scenario without seeding and (b) for a scenario with Ne seeding452 The dashed lines indicate the observation domain of the bolometer (whole poloidal plane in the triangular cross section), HEXOS (mid plane in the triangular cross section $)\left(\phi=36^{\circ}\right)$ and the divertor spec- ${ }^{454}$ troscopy (above the horizontal target at $\phi \approx 12.3^{\circ}$ ). The separatrix at the triangular cross section is shown in green. izontal divertor plate. The line emission of CIII is concentrated at a distance of $2-3 \mathrm{~cm}$ near the target at the begin of the discharge. The peak CIII emission reduces near the target after the first two neon injections (5 and $7 \mathrm{~s}$ ) and strongly reduces after the third injection (9 s). At the same time, the tail of the radiation increases in steps further in the perpendicular direction which corresponds to a movement towards the upstream location. After the last injection (11 s) signatures of strong upstream radiation occur before the radiative collapse. These results indicate a shift of the intrinsic radiation with enhanced neon seeding. The evolution of the CIII emission suggests that the plasma is clearly attached until about $7 \mathrm{~s}$ but then with the second and third puff driven closer to detachment with the CIII radiation front lifting off the target. In particular, from $9 \mathrm{~s}$ onward the radiation starts to vanish at the target until with the last puff at $11 \mathrm{~s}$ it completely detaches.

The impurity line emission measured with HEXOS [50] is considered to resolve the behavior of seeded neon. It also measures the intrinsic carbon radiation and thereby allows to provide evidence of $3 \mathrm{D}$ effects on the radiation distribution. The line of sight of this spectrometer is at a position located far away from any divertor target, in the midplane of the triangular cross-section, a cross-section without divertor targets. The time evolution of the line of sight integrated signals of the neon and carbon radiation are shown in figure 6(a) and (b). The line intensities of NeIV-VIII increase in correlation with the injection of neon and the enhancement of $P_{\text {rad }}$ every two seconds, starting at $5 \mathrm{~s}$ (figure 6(a)). The spectrometer is not calibrated. Therefore only changes in each line should be considered individually. Additionally, carbon line emission increases in the edge in correlation with the neon radiation. The strongest increase occurs for CII-CIV representing the lower charge states mostly radiating outside the LCFS while CV and CVI representing higher charge states remain mostly low and show only a moderate increase during high radiation after the third Ne injection (figure 6(b). This suggests an increase of total radiation not only by the additional line emission of seeded neon but also by an increase of the line emission of intrinsic impurities. The analysis of edge radiation based on localized measurements is an issue given the complex 3D SOL and divertor target geometry. Therefore, an attempt is made to analyze these features based on $3 \mathrm{D}$ modeling.

The 3D distribution of the CIII (465 nm) line emission has been modeled with EMC3-EIRENE and is shown in figure 7(a) and (b) for a scenario without and with $\mathrm{Ne}$ seeding $\left(\Delta P_{\text {rad }, N e}=2.3 \mathrm{MW}\right)$. The toroidal view goes out of the divertor region to the triangular shaped cross section (the green dots represent the separatrix). The horizontal and vertical divertor targets are located in the left upper corner. The dashed lines indicate the lines of sight of the bolometer, HEXOS, and the divertor spectroscopy. The carbon line emission is concentrated in the main erosion and recycling zone on the divertor plates initially (figure $7(\mathrm{a}))$. The 3D distribution also explains the stronger 

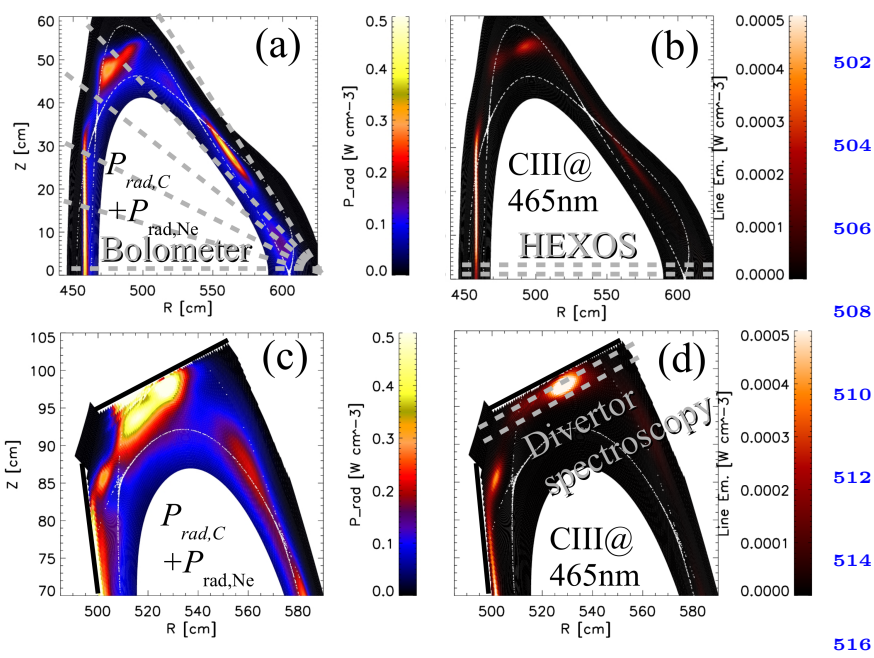

Figure 8: 3D modeling of a scenario with moderate $\mathrm{Ne}$ radiation (a) Total radiated power in the triangular plane. The dashed lines indicate the observation domain of the bolometer (whole poloidal plane) and HEXOS (mid plane) $\left(\phi=36^{\circ}\right)$ (b) CIII emission in the 20 triangular plane. (c) Total radiated power in the divertor domain $\left(\phi=12.3^{\circ}\right)$. (d) CIII emission in the divertor domain. The dashed line indicate the observation of the divertor spectroscopy.

intrinsic radiation at the inboard side. The impurities 26 eroded from the vertical divertor target are released into the island connected to the inboard island in the triangular ${ }_{28}$ plane. The impurities eroded from the horizontal target are released into the island connected to the top island in the triangular plane. The bottom divertor on the opposite ${ }_{30}$ side in the next field period will correspondingly connect to the bottom island and the inboard island (figure $7(\mathrm{a}))_{532}$

In response to Ne cooling the carbon line emission decreases in the divertor region (divertor spectroscopy) and ${ }_{34}$ enhances in the triangular plane (HEXOS and bolometer) as shown in figure 7 (b). This might explain the oppos 536 ing signal evolutions in the experiment discussed before. At the same time, the radiation also increases in the out 538 board islands connected to divertor modules further away. The 2D distribution of the total radiated power and the $\mathrm{e}_{40}$ CIII (465 nm) line emission is shown in figure 8(a) and (b) in the triangular plane and the divertor region for $\mathbf{a}_{42}$ medium level of Ne radiation $\left(\Delta P_{\mathrm{rad}, \mathrm{Ne}}=1.7 \mathrm{MW}\right)$. The dashed lines indicated the lines of sight of the diagnostics544 The white dots represent the separatrix. The radiation is mostly retained in the SOL.

These results show that the impurity radiation features a complex 3D distribution which is sensitive to the plasmas 48 state. Therefore it is difficult to interpret it based on a single local measurements only. The poloidally and radisso ally integrated $P_{\text {rad }}$ and CIII emission are shown in figure 9 (a) and (b) for the case without Ne, with low, medium 52 and high Ne radiation level. The radiation is mostly concentrated in the divertor region. The effective mains4 plasma-surface interaction zone and impurity sources extends toroidally from $\phi \approx 0-18^{\circ}$ within one half-field periods 56

(determined by the configuration and the geometry of the main PFCs). In the case without seeding, $P_{\text {rad }}$ is determined by carbon line emission and decreases toroidally from the divertor towards the bolometer in the triangular plane (figure 9(a)). The ratio of maximum divertor radiation $P_{\text {divertor, } \max }$ and radiation observed in the bolometer plane $P_{\text {bolometer }}$ is in this case $P_{\text {bolometer }} / P_{\text {divertor, } \max } \approx 57 \%$. This ratio increases with increasing neon radiation from $82 \%, 92 \%$ to $103 \%$ for $P_{r a d, N e}=1.0,1.7$ and $2.3 \mathrm{MW}$. Due to cooling of the SOL, the main radiation zone moves further upstream and into the confinement region towards the heat source. The radiation will equilibrate toroidally within flux tubes of almost constant temperature in the confinement region. This shows that the bolometer is more accurate for high radiation scenarios and the domain of closed flux tubes. The 3D effects in the radiation distribution may explain why divertor radiation might be underestimated in lower radiation scenarios and $\frac{P_{\operatorname{rad}}}{P_{E C R H}}>1$ occasionally occurs despite calibration.

Similarly, modeling results may explain the contrary evolution of the CIII emission measured in the divertor and with HEXOS (figure 5(b) and 6(b)). The results in figure 9 (b) show a decrease of the CIII emission in the divertor and an increase of in the triangular plane $\left(\phi=36^{\circ}\right)$ in response to cooling by neon radiation. The calculations with EMC3-EIRENE show that the total CIII emission remains almost constant and the total carbon radiation even slightly increases despite the reduction of the carbon flux.

Impact on divertor heat and particle fluxes. The divertor heat loads were usually measured with nine infrared cameras providing an almost $90 \%$ coverage of the divertor target plates [45, 46]. In case of the specific discharge investigated here in detail unfortunately only, eight divertor cameras were available. The $2 \mathrm{D}$ mapping of the heat fluxes with time on the divertor target of the lower and upper divertor in half-module 20 is shown in figure 10 (a). The heat flux mapping is shown between the Ne injections. The peak heat fluxes of the two major strike lines on horizontal and vertical tiles reduce after each injection and vanish in detachment eventually almost completely (figure 10(a)). The evolution of the toroidally averaged profiles across the horizontal target are shown for a top and a bottom divertor in figure 10 (b) and (c) before and after the sequence of four Ne injections. An averaged peak heat flux of $\left\langle q_{d i v}\right\rangle \approx 1.5 \mathrm{MWm}^{-2}$ is reduced by $50 \%$ after the first Ne injection and is reduced further to eventually below $0.5 \mathrm{MWm}^{-2}$ (figure 10 (a)). The heat flux in figure 10 (c) behaves similarly, but is slightly lower due to an inherent top-bottom asymmetry. Furthermore, an inherent small horizontal offset of the heat flux profiles in opposite directions is observed on all divertor targets when comparing upper and lower target plates. This may be related to poloidal flows $v_{\theta}$ induced by $E_{r} \times B$ drift effects [63].

The evolution of the integrated divertor heat fluxes $q_{d i v}$ is shown for all eight observed divertor modules in figure 11. The divertor heat fluxes are moderately higher on 

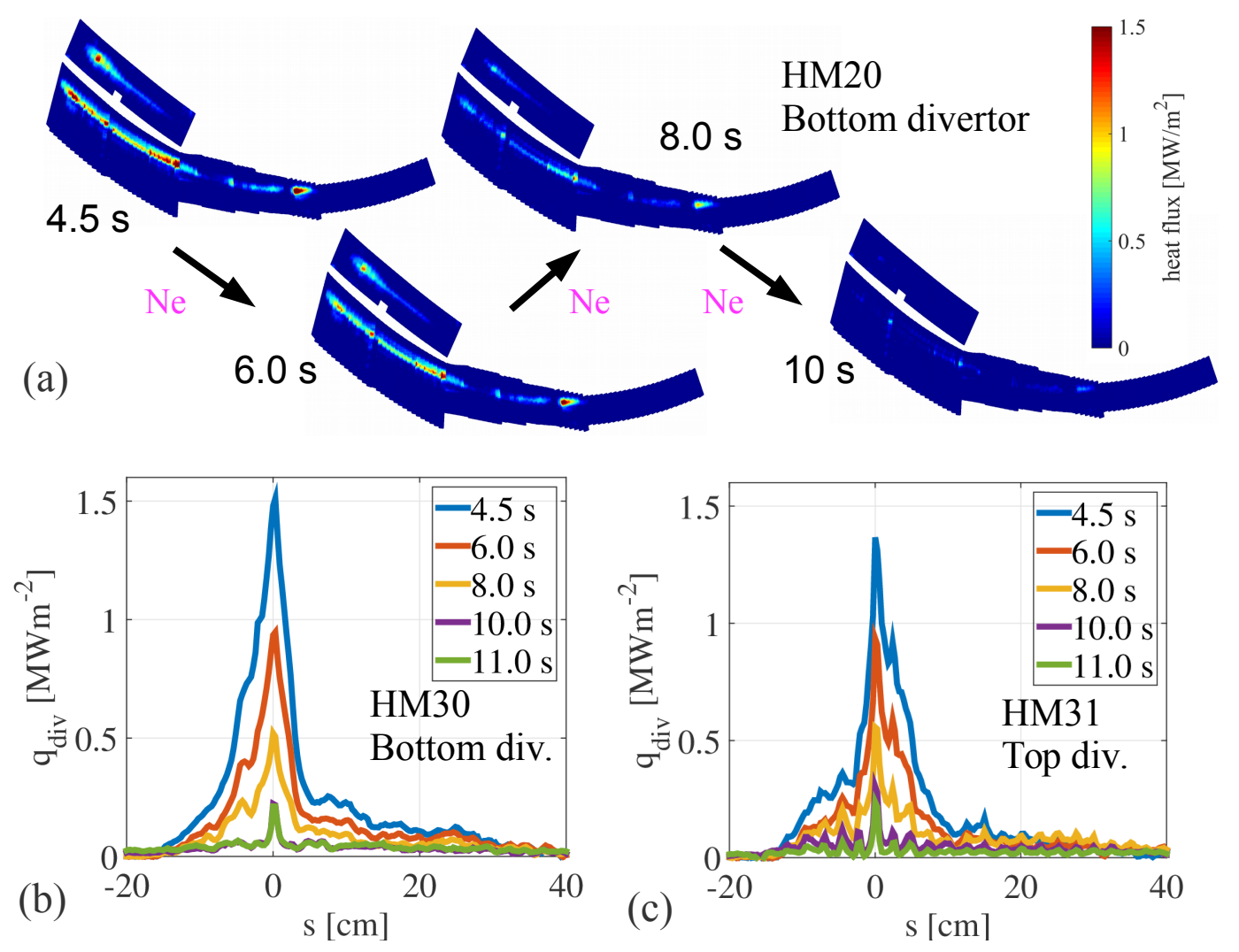

Figure 10: (a) Divertor heat loads before and after each Ne injection for HM20 (bottom divertor). (b) Averaged bottom divertor heat flux profiles across the horizontal target in HM30. (c) Averaged top divertor heat flux profiles across the horizontal target in HM31.

the bottom divertors $(+10 \%)$ compared to the top ones in this plasma scenario. Neon seeding causes a symmet584 rical reduction of the total heat fluxes on all divertors. The evolution of the global divertor heat load $\left(\Sigma_{i} q_{d i v, i}\right)$ is therefore representative for the total heat loads $q_{d i v, i}$ on $^{58}$ each divertor. The stepwise decrease of the heat load is correlated to the stepwise enhancement of $P_{\text {rad }}$ shown in in $^{58}$ figure 3(a) which in turn is correlated to the Ne injection. The total deposited power to the divertors captured by the $\mathrm{f}^{90}$ IR cameras is before seeding $q_{d i v} \approx 3.3 \mathrm{MW}$ and reduces by $\Delta q_{\text {div }} \approx 1.0 \mathrm{MW}$ to $2.2 \mathrm{MW}$ after the first Ne injection. ${ }^{592}$ The second and third Ne pulse reduce the deposited power by $\Delta q_{d i v} \approx 0.6-0.7 \mathrm{MW}$ to $q_{d i v} \approx 1.5 \mathrm{MW}$ and $0.9 \mathrm{MW}$.

A typical example for the evolution of maximum peak ${ }_{596}$ heat fluxes on the horizontal and vertical targets of the divertors in HM20 and HM21 is shown in figure 11(c). Those scatter between $q_{d i v, \text { max }} \approx 1.5$ and $6 \mathrm{MWm}^{-2}$ initially. Asymmetries of the local heat fluxes and distribution of hot spots are a common feature in attached plasma state 39. Error fields may modify the magnetic boundary and enhance local miss-alignments between the magnetic field and leading edges [64, 65. These local high heat fluxes are also reduced stepwise to $1-2 \mathrm{MWm}^{-2}$ after three $\mathrm{Ne}^{604}$ injections.

This demonstrates that Ne seeding allows for reliable and stable reduction of the divertor loads by $75 \%$. Theos divertors receive only $23 \%$ of the injected $P_{E C R H}$ during the high radiation phase.

The divertor particle flux $\Gamma_{d i v}$ is approximated by the ion saturation currents measured locally with the Langmuir probe arrays, which are mounted spatially symmetrical on a top and a bottom divertor module in the same toroidal W7-X module (HM50 and HM51, figure 1). It measures in the vicinity of the strike line and is sensitive to any perturbation or asymmetry of the magnetic field affecting the strike line location (e.g., error fields [64]). Here, the evolution of the particle flux is approximated by the total ion saturation current from all probes $J_{s a t}=\Sigma_{i} j_{s a t, i}$. The time evolution of the ion saturation current is shown in figure 3 (e) for lower and upper divertor (black and blue, respectively). The offset between the top and bottom divertor may be due to the asymmetries mentioned above. The particle flux shows a reduction correlated to the reduction of the heat fluxes. The ion saturation current at the lower divertor eventually reduces after the third neon injection by $\approx 70 \%$. The behavior at the upper divertor is similar despite the asymmetry. This result demonstrates that the particle fluxes (and consequently the associated convective heat fluxes) can be controlled by radiative power dissipation with Ne seeding as well. This reduction of downstream particle fluxes is also in agreement with the flow measurements discussed in the following. 

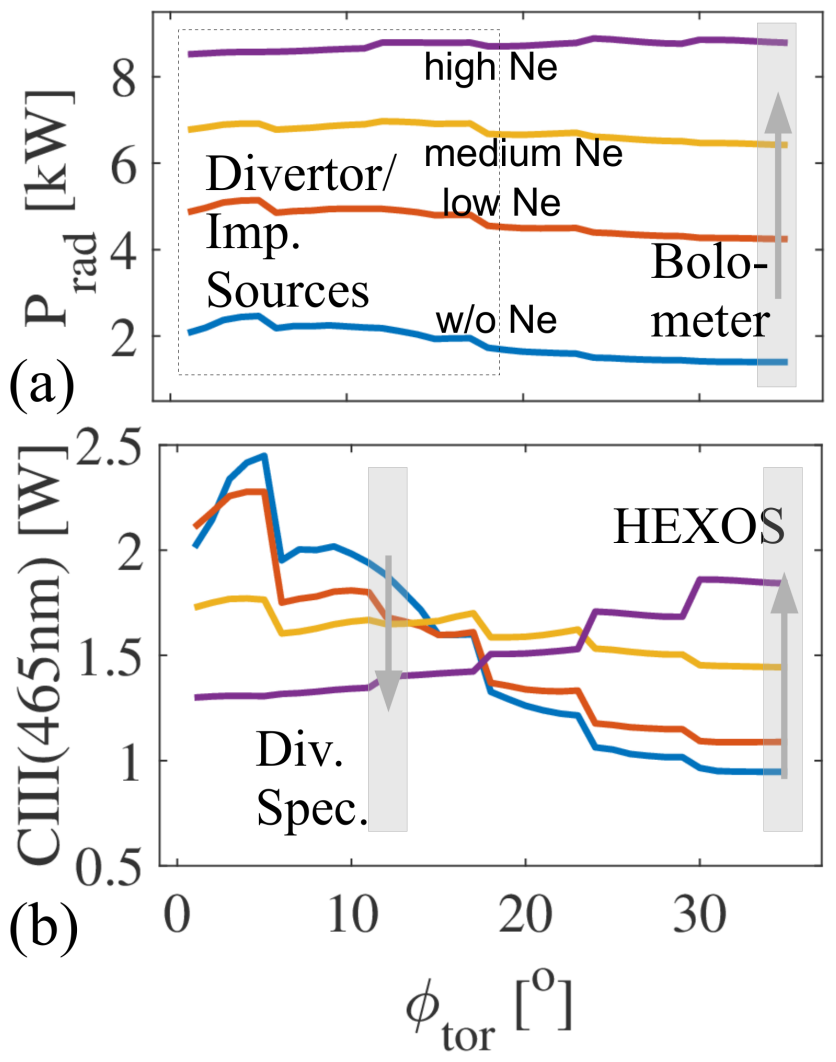

Figure 9: 3D modeling: (a) Toroidal distribution of total radiated power $P_{\text {rad }}$. The impurity sources (carbon divertor, neon source) are located in the divertor region which extends in a half field period from $\phi \approx 0-18^{\circ}$. The bolometer is located at $\phi \approx 36^{\circ}$. (b) Toroidal distribution of CIII(465 nm) emission. The divertor spectroscopy is located at $\phi \approx 12^{\circ}$. The HEXOS is located at $\phi \approx 36^{\circ}$.

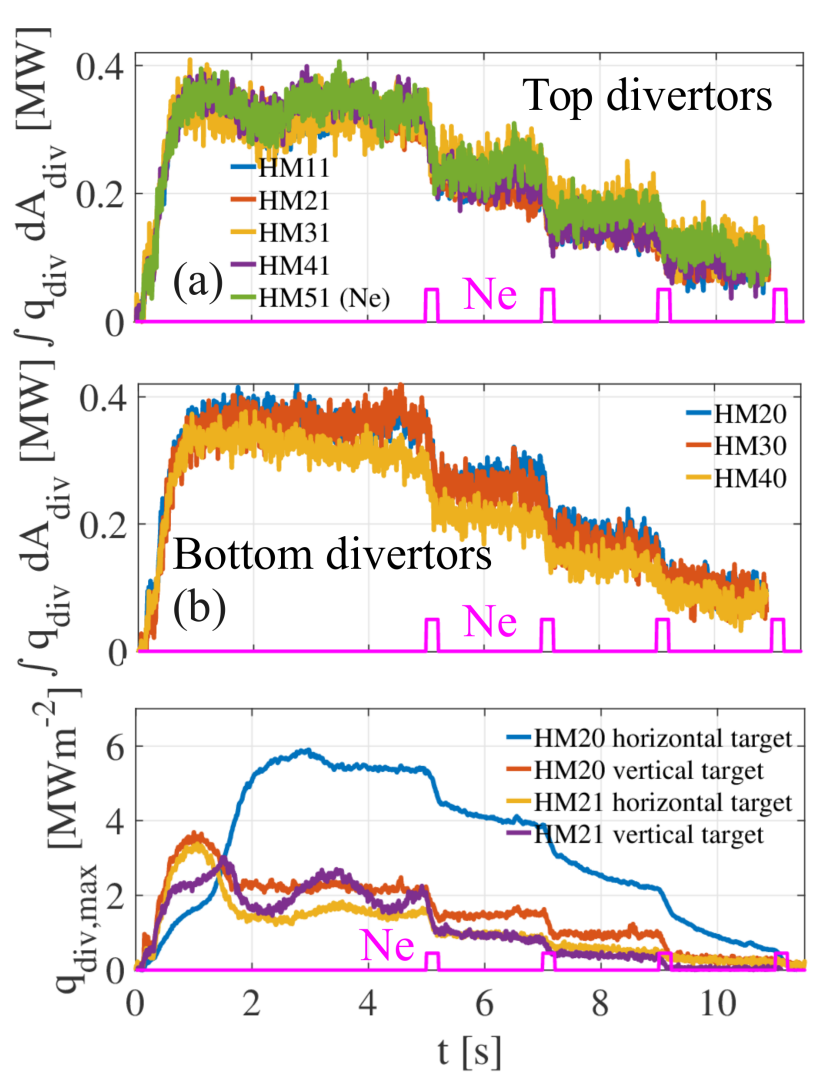

Figure 11: (a) Total top divertor heat loads. Ne seeding is performed in the HM51 divertor (green). (b) Total bottom divertor heat loads. (c) Maximum heat fluxes on horizontal and vertical targets of bottom and top divertor HM20 and HM21. 


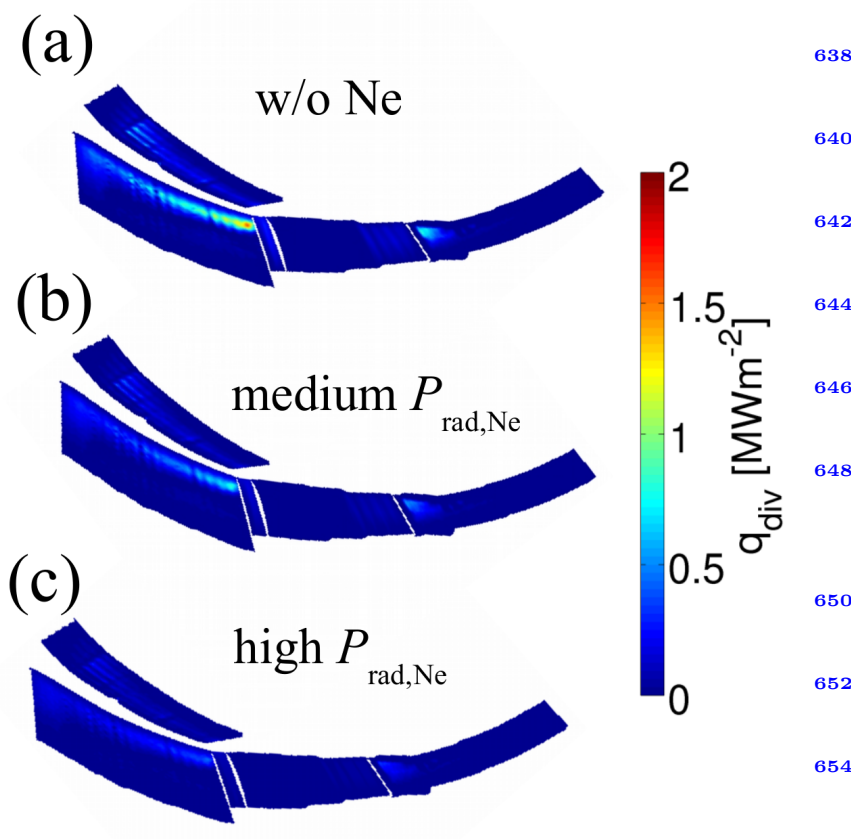

Figure 12: 3D Modeling of divertor heat fluxes assuming (a) intrin658 sic carbon source only, (b) neon impurities sourced from the main recycling domain for medium $\left(P_{\mathrm{rad}, N e}=1.7 \mathrm{MW}\right)$ and (c) high radiation $\left(P_{\mathrm{rad}, \mathrm{Ne}}=2.3 \mathrm{MW}\right)$
3D modeling confirms the dissipative reduction of $\mathrm{di}^{664}$

vertor heat fluxes treating Ne like a high recycling species. This is shown in figure 12 (a-c) for three cases. In the first case, only power losses from intrinsic carbon are assumed. In the second case additional power losses of $P_{r a d, N e}=1.7$ MW cause a significant reduction of the heat fluxes. For ${ }^{666}$ additional power losses of $P_{\mathrm{rad}, \mathrm{Ne}}=2.3 \mathrm{MW}$ by Ne impurities a detached state similar to the experiment has been established. Effects of currents, plasma response and error fields which may modify the magnetic boundary and change the details of the heat flux distribution are not taken into account in 3D transport modeling at this point.

The reduction in particle flux also indicates a reduced ${ }_{674}$ recycling flux. Since no hydrogen gas fueling was performed during the seeding cycle the effect of a slight $\operatorname{step}_{\overline{6} 76}$ wise density decrease in response to each Ne injection was measured. The time evolution of line integrated density ${ }_{678}$ $\int n_{e} d l$ and diamagnetic energy $W_{d i a}$ figure $3(\mathrm{~b})$ show a total drop of $10-15 \%$ after the third Ne injection. At the same time the core electron temperature increases from $T_{e, \text { core }} \approx 3.7 \mathrm{keV}$ to $4.6 \mathrm{keV}$. The temperature profile $\mathrm{be}_{\overline{6}}$ came more peaked due to the loss of particles from the confinement region. The energy confinement time is esti $\overline{\overline{6}}_{\mathbf{8}}$ mated based on the nominal input power of $4 \mathrm{MW}$. It is $\tau_{E} \approx \frac{\Delta W_{d i a}}{P_{E C R H}} \approx 130 \mathrm{~ms}$ before Ne seeding and reduces after ${ }_{886}$ the third Ne injection to $\tau_{E} \approx 110 \mathrm{~ms}$.

Additionally, a reduction in divertor neutral pressure dess8 picted in figure 3(e) for a lower and upper divertor (black and blue curve), was measured. The enhancement of the edge radiation induces degradation of line integrated density, recycling flux, and neutral pressure. In particular, the pressure loss is not desirable because it means a reduced neutral compression which is essential for particle exhaust. The reason for the loss of density and neutral pressure is unclear at the moment. The reduction of parallel particle flow velocities might result in a more effective perpendicular transport to the walls by anomalous diffusion. An analysis of this phenomenon is beyond the scope of this work. (In the $\mathrm{N}_{2}$ seeding experiment discussed later, such particle losses have been compensated by feedback-controlled divertor fueling.)

Damping of counter-streaming SOL flows. The SOL flow structures have been measured with the CIS diagnostic [48, 49] and are shown in figure 13. The camera view is directed in the toroidal direction roughly tangential to the magnetic axis. The poloidally alternating red and blue structures correspond to the counter streaming flows which are a characteristic feature of $\iota=5 / 5$ island divertor scenarios (compare figure 1(a)). The measurement of these predicted counter streaming flows was recently reported and explained in further detail in 49. They are driven by the parallel pressure gradients along the helical open magnetic flux tubes within the islands. Particle flows are directed from the higher pressure upstream region (LCFS) to the sinks downstream (divertor targets).

The flow behavior strongly determines the particle fluxes and consequently the convective heat fluxes in the SOL:

$$
\Gamma_{\|}=n V_{\|} \rightarrow q_{\|, \text {conv. }}=k_{B} T n V_{\|}
$$

The evolution of the island SOL flows is shown before and after the Ne injections in figure 13 (a-d). After the second and third Ne injection (7.5 s and $9.5 \mathrm{~s})$ the measurement shows damping of the flows. Shortly after the fourth $\mathrm{Ne}$ injection (at $t=11.3 \mathrm{~s}$ ) the plasma becomes unstable and the radiation moves inward resulting in the flows getting close to a complete standstill (figure $13(\mathrm{~d})$ ). A representative measure of the ion flow velocity $<v_{\|}>$ has been obtained by averaging over a small domain within one flow channel (compare black $100 \times 100$ pixel square in figure 13 (a). The time trace of this mean ion flow velocity is shown in figure $13(\mathrm{e})$. Clear damping is shown in correlation to each Ne injection. The flow velocity drops from $<v_{\|}>\approx 20 \mathrm{kms}^{-1}$ to $<v_{\|}>\approx 6 \mathrm{kms}^{-1}$ after three Ne injections still allowing for stable operation. This corresponds to a velocity reduction of $70 \%$. The time evolution of the velocity is correlated with the increase in $P_{\text {rad }}$. This global reduction of the SOL flows confirms that the convective part of the total heat loads is also reduced. The reduction of SOL flows and the reduction of particle fluxes measured downstream by $J_{\text {sat }}$ (figure 3(e)) provide substantial evidence for a direct link between the particle convection into the divertor and its dependence on the radiated power. 

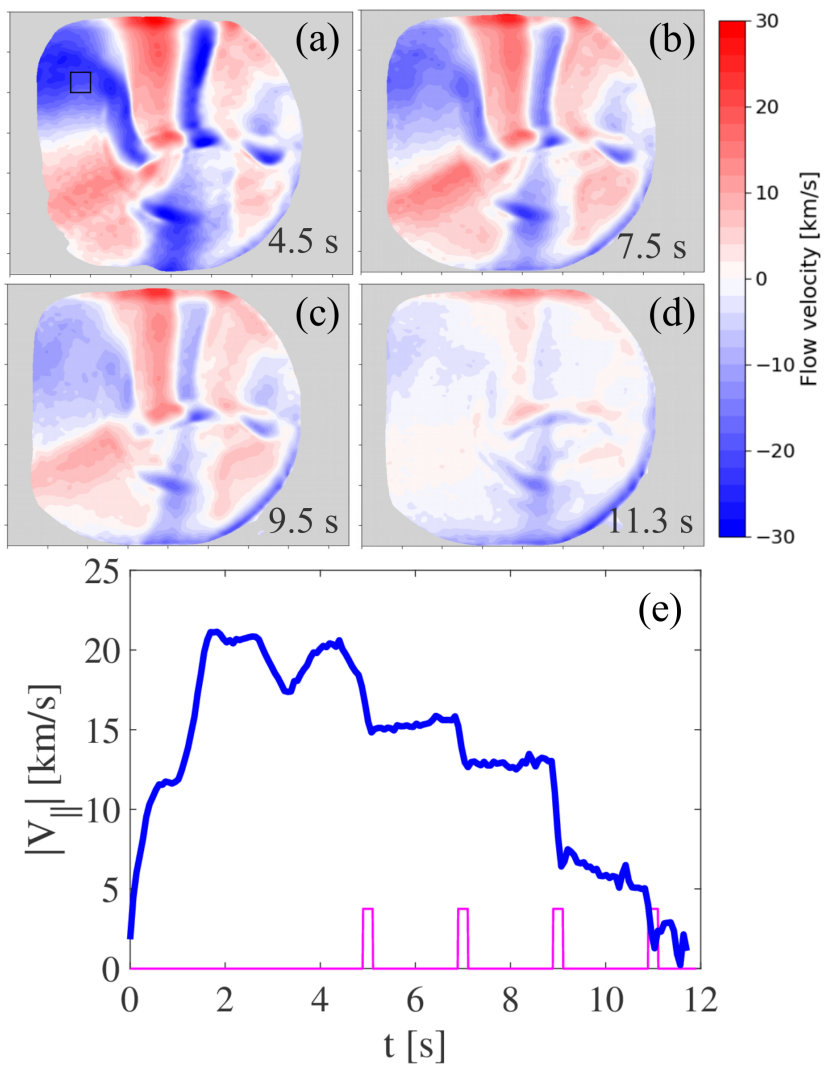

Figure 13: Ion velocity measurement by coherence imaging spectroscopy(CIS) (a) before neon injection, (4.5 s) (b) after two neon injections $(7.5 \mathrm{~s}),(\mathrm{c})$ after three neon injections $(9.5 \mathrm{~s}),(\mathrm{d})$ after four neon injections $(11.3 \mathrm{~s})$. (e) Time trace of average ion flow velocity $\left|V_{\|}\right|$(average taken in domain of black square mark).

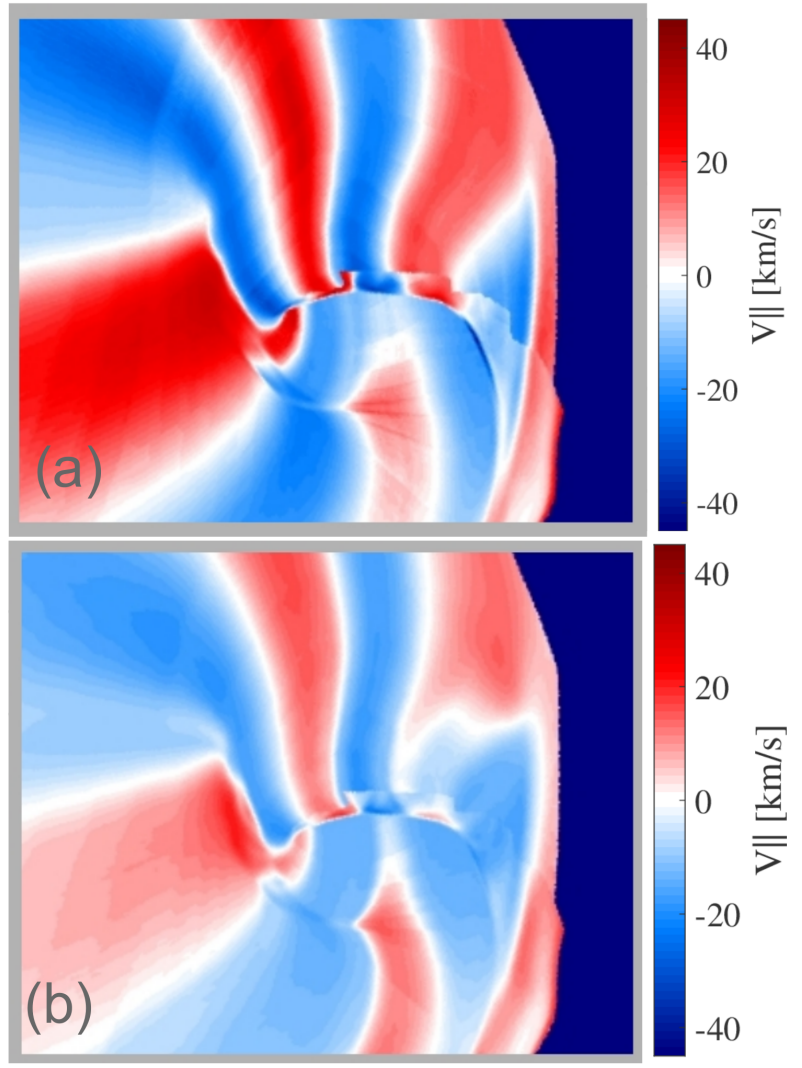

Figure 14: 3D ion flow velocities $V_{\|}$obtained from modeling: (a) without seeding. (The box represents rotated camera view from CIS.), (b) at high Ne radiation $\left(\Delta P_{r a d, N e}=+2.3 \mathrm{MW}\right)$. 


\section{Effects of $\mathrm{N}_{2}$ seeding} 48, 49].
The flow damping in response to radiative losses induced by seeding is confirmed by 3D modeling. The thermal pressure and the upstream to downstream pressure ratios drop by $\approx 30 \%$ and $55 \%$ in response to medium and strong edge cooling by Ne seeding in representative island flux tubes near the separatrix. Note that the upstream density is kept fixed in the modeling, while in the experiment additional density losses further reduce the pressure. The reduction of pressure is accompanied by a reduction of the plasma ion flows $n V_{\|}$by $50 \%-60 \%$ at the downstream location at maximum radiation. Additionally, a synthetic CIS measurement has been performed by calculating the flow patterns based on a CIII weighted ion velocity measurement approximating the experimental CIS 59. The results for a case without seeding and a case with high neon radiation are shown in figure 14(a), (b). This supports the observation in the experiment - the modeling shows actual damping of the flows purely due to the cooling of the SOL

Nitrogen seeding has been investigated for a scenario at a higher density and heating power (experiment ID \#20181016.023) and slightly changed island geometry (additional control coil currents $I_{c c}=1 \mathrm{kA}$. The evolution of the main discharge parameters is shown in figure 15. The heating power is kept constant at $P_{E C R H}=4.7 \mathrm{MW}$ in $O 2$-Mode and is shown with the total radiated power $P_{\text {rad }}$ and the power deposited on the divertors $P_{d i v}$ in figure 15(a) (black, red and blue curves). The line integrated density is kept constant at $\int n_{e} d l \approx 9 \cdot 10^{19} \mathrm{~m}^{-2}$ by active feedback-controlled fueling through the divertor gas box in HM51 as shown in figure 15(b) (black) together with the diamagnetic energy (blue), the core electron temperature $T_{e, c o r e}$ (red) and the $\mathrm{H}_{2}$ gas fueling rates (main gas system: green, divertor feedback-control: cyan). This feedback-control by divertor gas puff has been used in combination with (pre-programmed) $\mathrm{N}_{2}$ seeding here for the $\oplus^{46}$ first time to counter-balance density losses which happen otherwise as in the Ne seeded scenario discussed before 48 The edge electron temperature at the LCFS (figure 15(c)) is initially $100 \mathrm{eV}$ and shows a reduction in correlatiorrso with increasing $P_{\text {rad }}$ induced by continuous $\mathrm{N}_{2}$ seeding in HM30. A minimum edge temperature of $T_{e, e d g e} \approx 20-25$ eV 552 was achieved before the seeding has been terminated. The core electron temperature of $T_{e, \text { core }} \approx 2.6 \mathrm{keV}$ is sustainects4 (figure 15(b)). After the injection, the edge temperature recovers and reaches $75 \mathrm{eV}$ before pre-programmed termination of the discharge. Much lower temperatures haves6 been observed close to the target. However, those are below the sensitivity of Thomson scattering.

The effective charge state $Z_{\text {eff }}$ is shown in figure 15(d). The effective charge state is $Z_{\text {eff }} \approx 1.2$ at the beginning6o and suggests $Z_{\text {eff }} \approx 2.1$ before termination of $\mathrm{N}_{2}$ injections. A maximum concentration of $c_{N 2} \approx 2.5 \%$ in the ${ }_{62}$ core is estimated in this case. This suggests in turn that
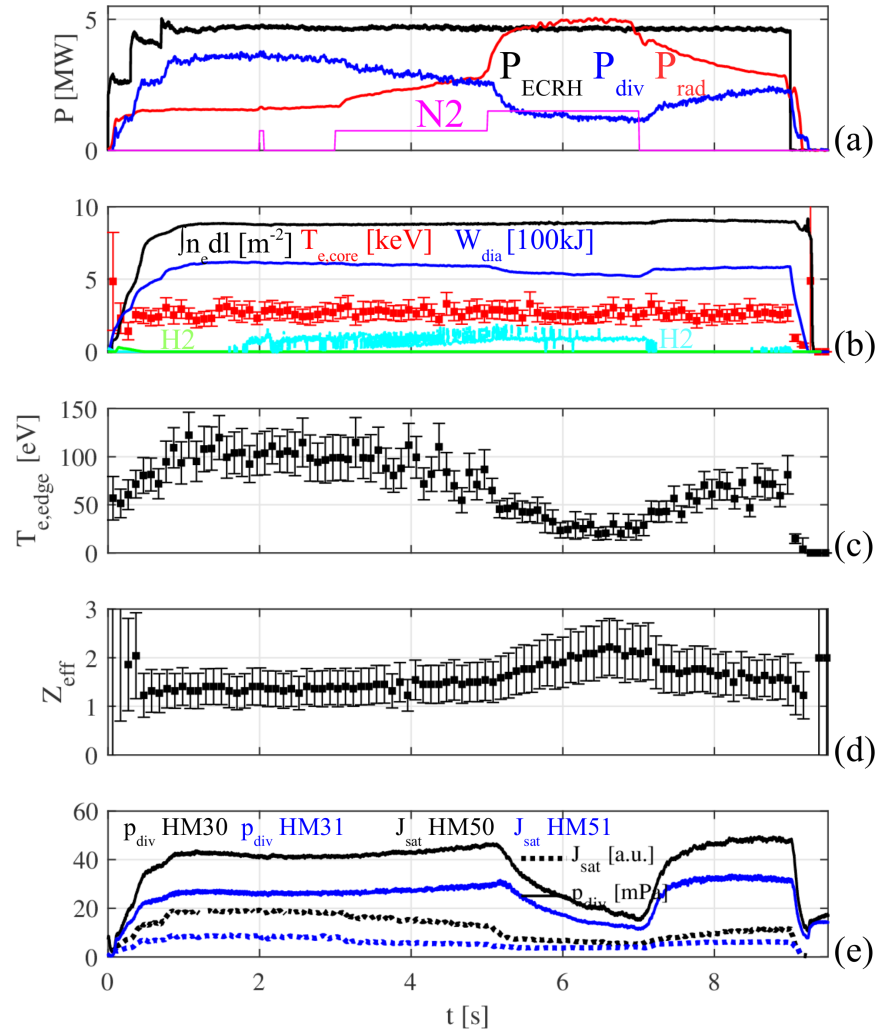

Figure 15: Time evolution of scenario with $\mathrm{N}_{2}$ seeding (\#20181016.023). (a) injected heating power (black) radiated power (red), power deposited on divertor (blue), $\mathrm{N}_{2}$ seeding rate from gas box in HM30 (magenta) (b) line average density (black) and plasma stored energy $W_{\text {dia }}$ (blue), core electron temperature $T_{e, \text { core }}$ (red) from Thomson scattering (V10) near axis, $\mathrm{H}_{2}$ fueling rates from main gas inlets (green) and HM51 divertor gas box (cyan), (c) Thomson scattering edge temperature (at the separatrix, V10), (d) effective charge state $Z_{\text {eff }}$, (e) neutral pressure $p_{d i v}$ and local particle fluxes $J_{\text {sat }}$ at lower (black) and upper (blue) divertor.

less than $3.6 \%$ of the total number of particles injected accumulate in the core.

The total ion saturation currents $J_{\text {sat }}$ and divertor neutral pressures $p_{d i v}$ are shown in figure 15 (e), respectively, for lower (black) and upper divertor (blue). The center of the strike lines is rather off by $40 \mathrm{~mm}$ from the Langmuir probe arrays in this configuration such that the $J_{\text {sat }}$ measures the outer tail of the ion flux distribution across the horizontal target rather. Nitrogen seeding has been performed with the bottom gas box (half module 30) close to the bolometer.

Features of the $3 D$ radiation distribution. The seeding scheme for $\mathrm{N}_{2}$ injection is different from the Ne seeding scheme based on the experience from first experiments in the limiter configuration [66 and first tests in the island divertor configuration. The flow rate of $\mathrm{N}_{2}$ is $\Gamma_{N 2} \approx 10^{20}$ molecules per second initially. At $t=2 \mathrm{~s}$ a first short $\mathrm{N}_{2}$ injection of $50 \mathrm{~ms}$ is performed. The bolometer shows almost no response in the $P_{\text {rad }}$ (figure 15 (a)). Starting at $t=3$ 

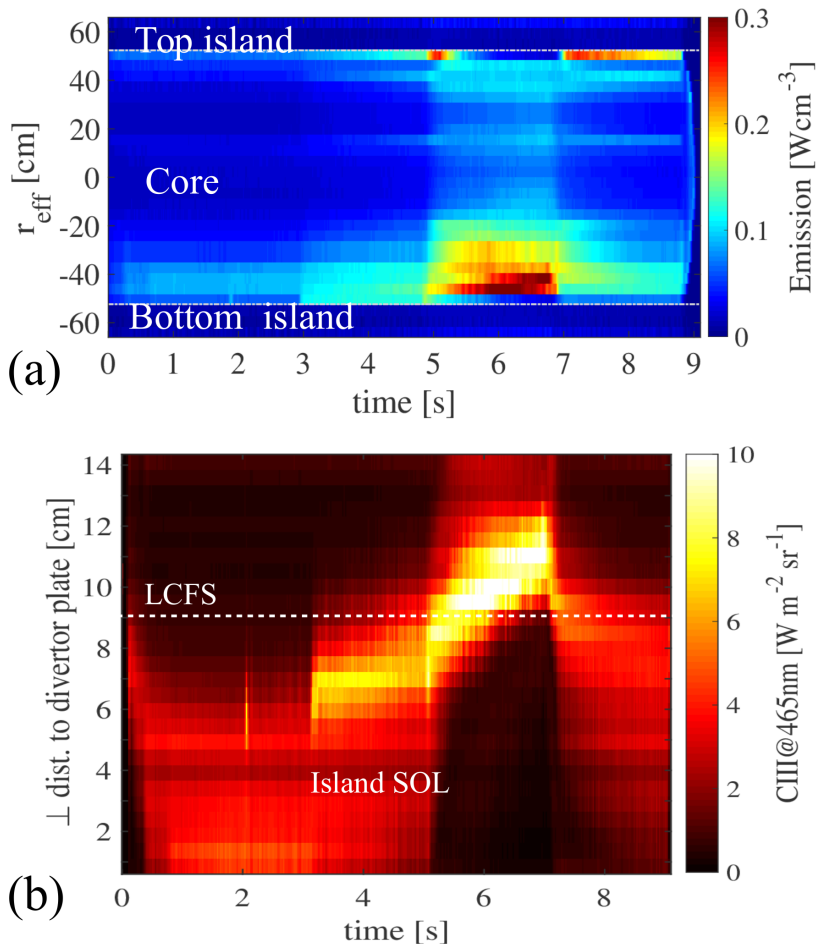

Figure 16: (a) Time evolution and vertical distribution of chord- ${ }^{792}$ brightness (composing the total radiated power $P_{\text {rad }}$ ) measured with the horizontal Bolometer camera. (b) HM30 ( $\mathrm{N}_{2}$ seeding) divertor 94 spectroscopy: CIII (465 $\mathrm{nm}$ ). $\mathrm{s} \mathrm{N}_{2}$ is released into the divertor continuously at the flow 98 rate mentioned above. In this case, the bolometer shows an almost linear increase of the total radiation. After 2 soo of continuous $\mathrm{N}_{2}$ injection, the radiation is enhanced by $100 \%$. At this point $(t=5 \mathrm{~s})$ the flow rate is doubled byoz opening a second gas valve $\left(\Gamma_{N 2} \approx 2 \cdot 10^{20}\right.$ molecules/s $)$ for a further 2 seconds. The bolometer shows almost $\gtrless^{04}$ jump in $P_{\text {rad }}$ and then again a linear-like increase. After termination of the $N_{2}$ injection at $(t=7 \mathrm{~s})$ the radiatioræo6 starts to decay immediately. First with a steep slope with an effective decay time constant of $\tau_{\text {Prad }} \approx 1.4 \mathrm{~s}$, followedo8 by a subsequent slower decay with a higher time constant of $\tau_{\text {Prad }} \approx 4.5 \mathrm{~s}$. The decay of $P_{\text {rad }}$ in response to long $\mathrm{N}_{2}^{10}$ injection is slower than the typical fast decay of a few hundred milliseconds in response to relatively short nitroge ${ }_{12}$ injections $(O(10-100) \mathrm{ms})$ typically observed.

The temporal and approximative spatial (vertical) diss14 tribution of the total radiated power $P_{\text {rad }}$ obtained from the Bolometer is shown in figure 16(a). The radiation ens16 hances after the start of continuous nitrogen injection (3 s) and increases rapidly after doubling the influx rate (\$18 s). The radiation is mainly enhanced in the domain of the bottom lines of sight crossing the seeded island which iszo connected to the source location in the neighboring divertor. Enhanced edge radiation is also seen in the top island22 until shortly after the $N_{2}$ flux rate into the bottom island increases by a factor of two after $5 \mathrm{~s}$. The radiation ens24

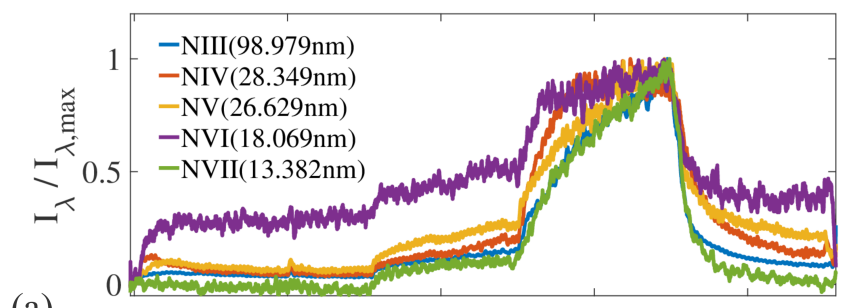

(a)

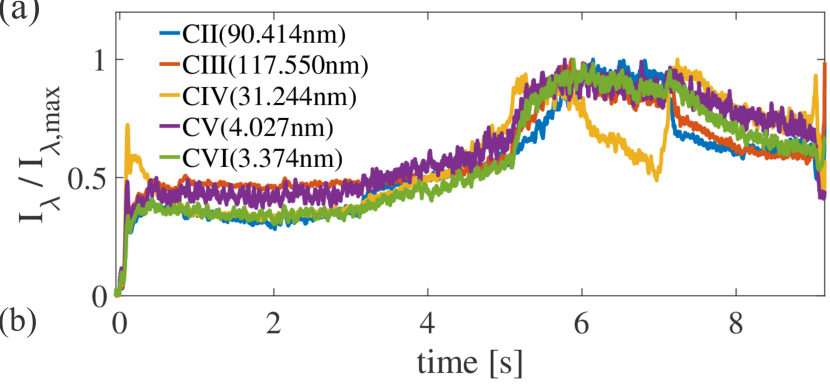

Figure 17: Overview spectrometer (HEXOS) lines for (a) nitrogen and (b) carbon. The line emission is measured at the midplane $(Z=0)$ in the triangular symmetry plane far away from the divertor.

hances then also deeper in the confinement near the top island. However, it is weaker than the radiation front in the bottom. After $7 \mathrm{~s}$ the seeding stops and the radiation decays until regular termination of the discharge. This indicates a stronger concentration of nitrogen line emission in the bottom island connected to the nearby source.

The effect of seeding on the major intrinsic radiator is shown in figure 16(b). Here, the evolution of the CIII(465 $\mathrm{nm}$ ) emission above the $N_{2}$ injection location in the HM30 divertor is shown. The emission profile shows the distribution across the island at various perpendicular distances from the divertor target. A short peak at $2 \mathrm{~s}$ correlates with the short $\mathrm{N}_{2}$ injection of $50 \mathrm{~ms}$ duration which shows no sustained effect in radiation enhancement. Starting at $t=3 \mathrm{~s}$ the CIII emission front is enhanced and detaches at higher influx rate after $5 \mathrm{~s}$ from the target and moves towards the separatrix (around $9 \mathrm{~cm}$ ). The dark region between $5 \mathrm{~s}$ and $7 \mathrm{~s}$ shows a clear sign of the strong cooling around the $\mathrm{N}_{2}$ cloud during the doubled $\mathrm{N}_{2}$ influx rate (figure 16(b)).

The line emission of the dominant extrinsic and intrinsic radiators nitrogen (NIII-NVII) and carbon (CII-CVI) as measured by HEXOS is shown in figure 17 (a) and (b). The nitrogen line emission increases for all charge states in correlation with the bolometer $P_{r a d}$ signal. (The NVI line shows some deviations due to some overlap with an ArXIV line which cannot be separated cleanly at this point.) This indicates an increasing concentration of higher charge states also in the confinement region when $Z_{\text {eff }} \approx 2.2$ (figure $15(\mathrm{~d}))$. It should be noted that the HEXOS line of sight does not cross the seeded island, yet observes a continuous enhancement. The carbon line emission moderately increases with nitrogen seeding (figure 17(b)). When the nitrogen influx rate is doubled at $5 \mathrm{~s}$, the carbon line 

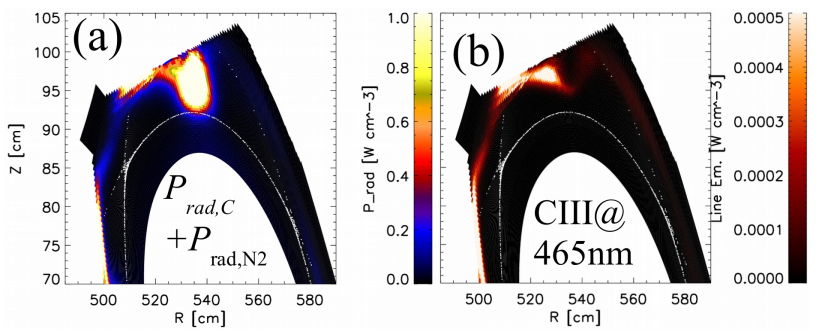

Figure 18: Distribution of (a) total radiated power and (b) CIII(465 $\mathrm{nm}$ ) obtained from 3D modeling at $\phi=12.3^{\circ}$ in the divertor region for $N_{2}$ injection in the island center $\left(\Delta P_{\text {rad,N2 }}=+1 \mathrm{MW}\right)$. The white dots mark the position of the separatrix.

emission saturates or even drops. A major increase in radiated power results from the nitrogen since its emission enhances by a factor of $\approx 10$ while the carbon line emission enhances only by a factor of $\approx 2-2.5$ (figure $17(\mathrm{a})$ and (b)).

3D modeling of the seeding and transport of partially recycling gases is more sophisticated and beyond the scope of this work due to heavy requirements to computational resources. A simplified approach based on the assumption of zero recycling and stellarator symmetry assumes a local $\mathrm{N}_{2}$ source in all divertors. The total radiated power and CIII line emission is shown in figure 18 (a) and (b) in the divertor region. The radiation is concentrated in the island $O$-point and results in a strong local cooling. The cooling suppresses the CIII emission in the island center. This may recover the effect seen in the CIII emission obtained in the divertor spectroscopy in figure 16(b) in a first attempt. If the $\mathrm{N}_{2}$ would be transported like a fully recycling gas a complete detachment of the CIII emission zone from the divertor target is anticipated.

Impact on divertor heat and particle fluxes. The total deposited power onto the divertors $P_{d i v}$ drops in correlation to the enhancement in $P_{\text {rad }}$ (figure 15(a)). It shows first a linear decay and then a sudden steep drop when the $\mathrm{N}_{2}$ flow rate is doubled. After termination of $\mathrm{N}_{2}$ seeding the divertor load starts to recover as the radiated power drops.

A representative heat flux mapping is shown for the lower divertor in HM30 in figure 19. The mapping is shown before, during and after the $\mathrm{N}_{2}$ injection. A difference to the situation with Ne seeding is the asymmetric cooling of horizontal and vertical targets. The strike line on the vertical target detaches first $(4.7 \mathrm{~s})$, while the strike line on the horizontal target is sustained for a longer time and detaches at $6.5 \mathrm{~s}$. After the seeding, the strike line on the horizontal target re-attaches while the one on the vertical target remains detached until the end of the discharge (not providing the time for complete re-attachment). This behavior indicates a more localized cooling and detachment in the divertor region compared to Ne. The reduction of heat fluxes and the detachment are less homogenous during a transient phase. Yet, a complete detachment of the

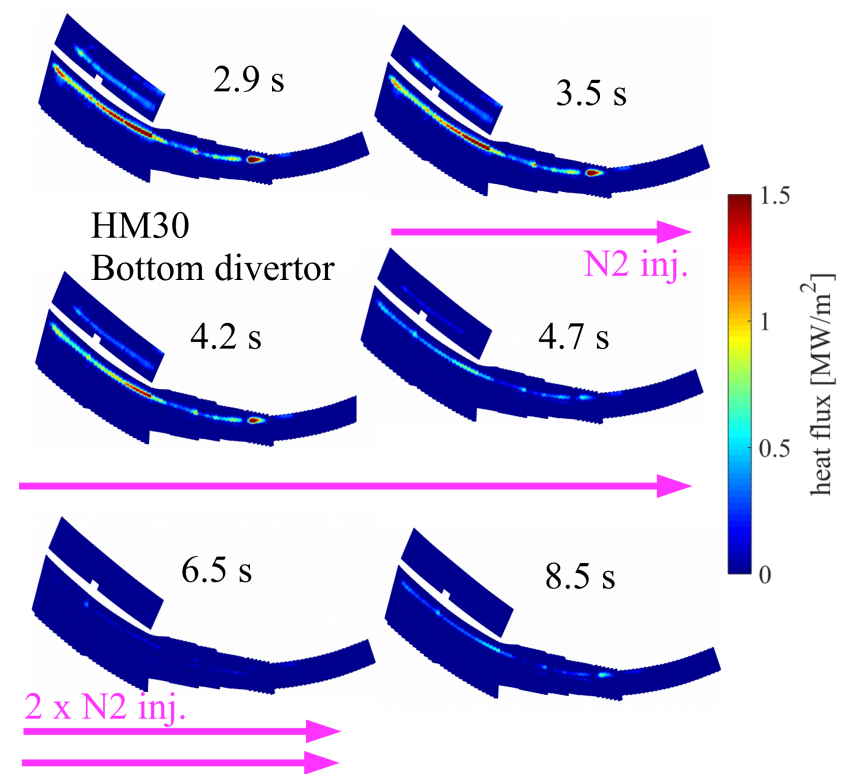

Figure 19: Bottom diveror heat loads (HM30) before, during and after $\mathrm{N}_{2}$ injection. Asymmetric cooling: the heat flux to the vertical target reduces first and does not recover after $\mathrm{N}_{2}$ injection.

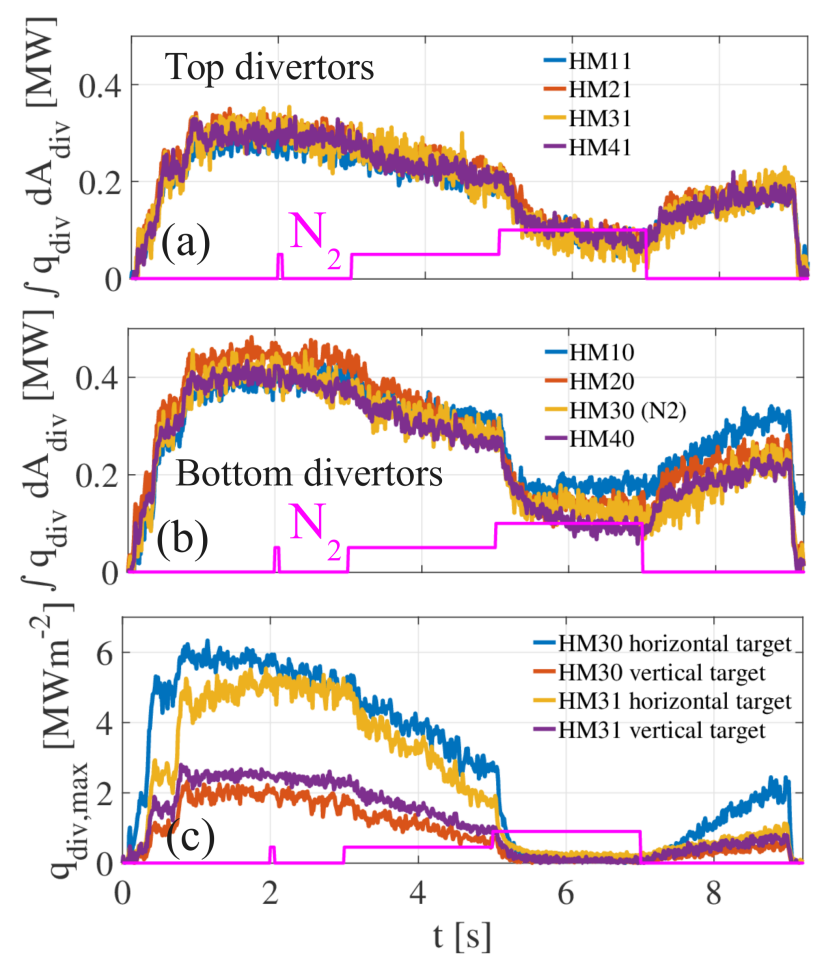

Figure 20: (a) Top diveror heat loads. $\mathrm{H}_{2}$ fueling is performed at the HM51 divertor (green). (b) Bottom divertor heat loads. $\mathrm{N}_{2}$ seeding is performed in the HM30 divertor (yellow). 
peak heat fluxes below $q_{d i v}=0.5 \mathrm{MWm}^{-2}$ was eventually achieved on the parts of all divertor targets.

The time evolution of the total heat loads $P_{\text {div }, j}$ to top and bottom divertors are shown in figure 20(a) and (b). Each of the individual divertor load signals shows a reduction in response to the radiative power losses induced by $\mathrm{N}_{2}$ seeding. Noticeable asymmetries in the divertor loads occur as offsets of $\Delta q_{d i v} \approx 0.1 \mathrm{MW}$ between the top and bottom divertor heat loads. The bottom divertors receive $25-30 \%$ more integrated heat fluxes than the top divertor. Smaller asymmetries in the heat load distribution are mostly caused by the $O 2$ heating scheme which tends to deposit more non-absorbed power on the divertor in HM51. The maximum heat fluxes $q_{d i v, \max }$ on horizontal and vertical targets of the bottom and top divertors in HM30 and HM31 are shown in 20(c). The peak maxima on the horizontal targets (blue and yellow) are initially about $q_{d i v, \text { max }} \approx 5-6 \mathrm{MWm}^{-2}$ and the ones on the vertical targets are only $q_{d i v, \text { max }} \approx 2-2.5 \mathrm{MWm}^{-2}$. The latter show earlier detachment in response to $\mathrm{N}_{2}$ seeding. Shortly after increasing the seeding rate the peak maxima completely vanish on horizontal and vertical target corresponding to a complete detachment.

The symmetric reduction of total heat fluxes on all divertors shows that $\mathrm{N}_{2}$ seeding allows for a global reduction of heat and particle fluxes and even detachment despite its lower recycling coefficient if seeded in a continuous mode. The relatively fast transport processes within the SOL may cause a saturation of the divertor targets with nitrogen after a short time and enhance the effective recycling. This in turn results in a more global distribution of the $\mathrm{N}_{2}$ and causing cooling also in island flux tubes not connected to the source location. This is a promising finding and shows that similar global radiative power exhaust with partially-recycling $\mathrm{N}_{2}$ is feasible as in case with high recycling gases such as Ne. The clear detachment and partial re-attachment after $\mathrm{N}_{2}$ injection indicates the feasibility of use of this impurity species for potential control of edge radiation and detachment based on a feedback control system 67, 68.

The divertor pressure shows a moderate and slow response of increase and eventually, a decrease during the high radiation phase after $5 \mathrm{~s}$. The line averaged density is maintained all the time (figure $15(\mathrm{~b})$ ) and is marginally overcompensated at the end of the discharge. The sudden jump in $P_{\text {rad }}$ after $5 \mathrm{~s}$ results in a marginal reduction of energy confinement. The achievement of a divertor heat flux detachment comes at the cost of a drop in diamagnetic energy of $W_{d i a} \approx 600 \mathrm{~kJ}$ by $13 \%$ at maximum radiation. The energy confinement time (estimated based on the nominal input power) drops from its original value of $\tau_{E}=133 \mathrm{~ms}$ to a minimum of $\tau_{E}=111 \mathrm{~ms}$ at maximum $P_{\text {rad }}$. After termination of the $\mathrm{N}_{2}$ injection at $7 \mathrm{~s}$ the divertor pressure, and the energy confinement starts to recover and approach their original levels.

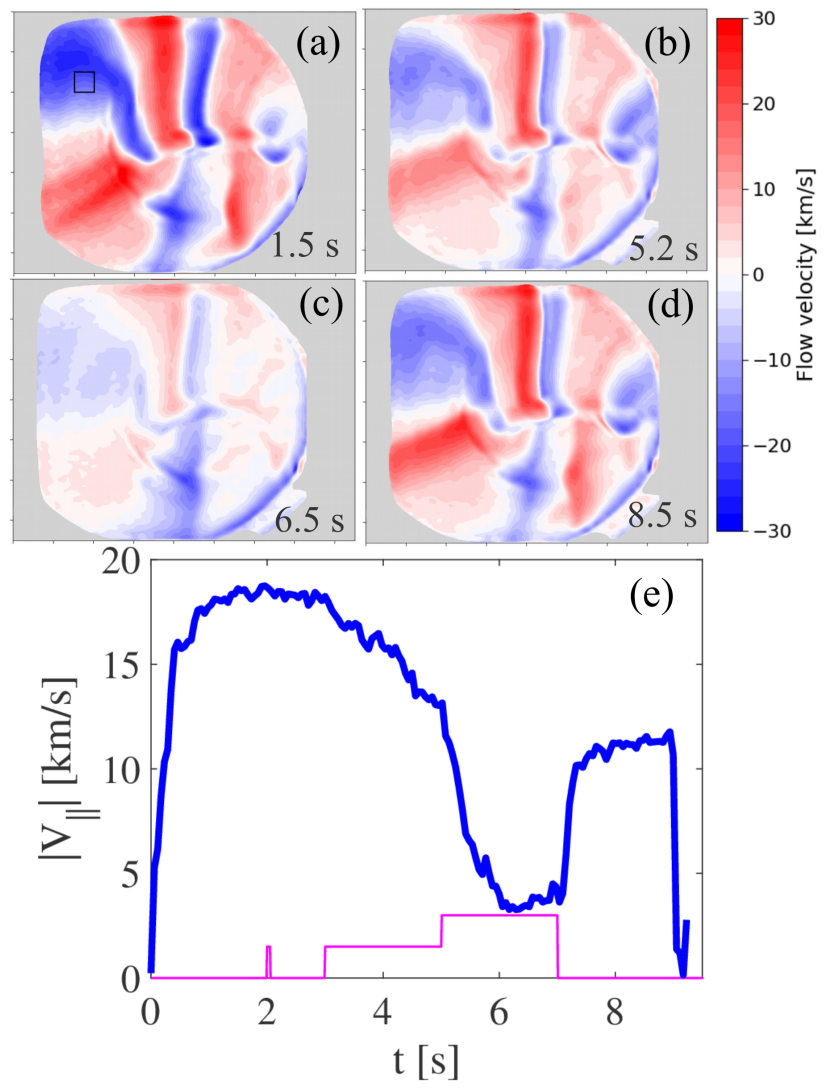

Figure 21: Ion velocity measurement by coherence imaging spectroscopy(CIS) (a) before nitrogen injection, (1.5 s) (b, c) during continues nitrogen injection $(5.2,6.5 \mathrm{~s}),(\mathrm{d})$ after termination of nitrogen injection $(8.5 \mathrm{~s})$. (e) Time trace of average ion flow velocity $\left|V_{\|}\right|$(average taken in domain of black square mark). 
Impact on counter-streaming SOL flows. A measte

\section{Discussion}

surement of the parallel ion velocity has been performed with the CIS diagnostic. The evolution of the counters78 streaming ion velocities is shown in figure 21 for representative time frames in figure 21(a-d) and for the time tracoso of the averaged $\left\langle v_{\|}\right\rangle$(figure 21(e)) in a representative flow domain (black mark in figure 21(a)). The velocity is 82 $<v_{\|}>\approx 18 \mathrm{kms}^{-1}$ before the seeding. The flow structures show strong damping when the nitrogen influx rate is dous84 bled after $5 \mathrm{~s}$ (figure 21(b), (c)). At the highest radiation level the flow velocity reduces to $\left\langle v_{\|}>\approx 3 \mathrm{kms}^{-1}\right.$ arounds6 $6.5 \mathrm{~s}$ (compare figure 21(c) and 21(e)). This corresponds to a strong drop in SOL particle fluxes and consequently ass strong drop in convective heat fluxes to the divertor. After the end of the nitrogen injection the flow velocity start\$so to recover and reaches $\left\langle v_{\|}>\approx 11.5 \mathrm{kms}^{-1}\right.$ before regular termination of the discharge (compare figure 21(d) andes $21(\mathrm{e}))$.

The results suggest a reduction and recovery of the ion 94 flow velocity in correlation with the evolution of the power dissipation induced by $\mathrm{N}_{2}$ seeding. The damping occurs im96 this scenario also while maintaining the upstream density and is therefore induced by cooling of the plasma edgøss temperatures only. The flow damping is in correlation with the measured reduction of $J_{\text {sat }}$ in the outer tail of thøo divertor particle fluxes and thereby also by $q_{d i v, c o n v}$. The ion flow velocity $V_{\|}$reduces globally and is correlated to 1هo2 controlled heat flux detachment induced by $\mathrm{N}_{2}$ seeding.

It has been demonstrated that radiative power exhaur can be controlled by impurity seeding with partially andos fully recycling gases. This, in turn, enables controlling the heat and particle fluxes, which is crucial for detachmentio control in future long-pulse and reactor relevant scenarios.

The results show that neon is reliable and effective tro12 achieve a high and stable level of radiative power exhaust and reduction of divertor heat fluxes. Its high recyclingig 14 property allows despite the localized gas inlet for a sustained increase in edge radiation and a sustained detacho16 ment while overcoming any barriers resulting from the 3D geometry of the independent magnetic island flux tubeso1s However, its high recycling coefficient and slow exhaust can be an obstacle since radiative power control should 20 also allow for a reduction of $P_{\text {rad }}$. The assumption of high recycling neon in the 3D modeling shows a uniform diser2 tribution of the radiative losses and results in a globally symmetric reduction of the divertor heat fluxes similar tiø24 the experiment.

Short $\mathrm{N}_{2}$ puffs do not result in a sustained enhanceer6 ment of $\mathrm{N}_{2}$ line emission. Continuous $\mathrm{N}_{2}$ injection allows for a controlled enhancement of $P_{\text {rad }}$ allowing eventualhyzes a global transition to detachment and re-attachment after termination of the injection. The slower decay of $P_{r d \boxplus 30}$ after long-pulse $\mathrm{N}_{2}$ injection might be caused by a saturation of the carbon walls with $\mathrm{N}_{2}$ resulting in a highess effective recycling coefficient. This enhanced recycling effect is sufficient to overcome the barrier of the 3D island flux tube structure and achieve global radiative power exhaust and detachment even by seeding through a localized source. The recycling and absorption behavior discussed here are similar to the effects reported in past studies at tokamak devices such as JET [16, 69] and recent studies at LHD [54, 70.

The experiments at W7-X show that $\mathrm{N}_{2}$ allows for better control of the radiation level (increase or decrease) and in turn of the heat fluxes (detachment and re-attachment) while Ne should be used with care due to its slow pumpout and resulting residence times of an order of magnitude longer compared to $\mathrm{N}_{2}$. Estimates based on the $Z_{\text {eff- }}$ measurements suggest maximum core impurity concentrations of $c_{N e} \approx 3.6 \%$ and $c_{N 2} \approx 2.5 \%$ corresponding to a screening of $75 \%$ and $95 \%$ of the $\mathrm{Ne}$ and $\mathrm{N}_{2}$ particles injected. This suggests that nitrogen causes less core dilution despite a higher seeding rate (ratio of total number of impurity particles released into the SOL: $\frac{N_{N 2}}{N_{N e}} \approx 15-20$ ).

Strong radiation enhancement by impurity seeding has caused a loss of density and neutral pressure in the experiments presented. This effect is opposite compared to the situation before boronisation where impurity seeding resulted in an density increase. The edge cooling and related reduction of parallel flows might result in a more effective outward directed diffusive transport yielding a loss of particles into some remote areas not covered by the measurements. However, these losses can be compensated by density control as demonstrated in the $\mathrm{N}_{2}$ seeding experiment in this work.

Damping of the three-dimensional counter-streaming island flows was observed in response to radiative edge cooling and most pronounced in case of high-level radiation with $\mathrm{Ne}$ and $\mathrm{N}_{2}$ seeding. Recovery of the flows was measured after nitrogen injection. 3D modeling supports the statement that the counter streaming island flows are reduced in response to the mitigation of the pressure gradient. Strong edge radiation mitigates the flows in the SOL and thereby the particle fluxes and convective heat fluxes to the divertors. This is in correlation with the heat flux detachment observed on the divertors.

3D modeling provides within the assumptions made an explanation of radiation asymmetries such as the simultaneous decrease and increase of CIII emission at different toroidal locations in response to neon seeding. At lower $P_{\text {rad }}$, the radiation is concentrated in the divertor and may be underestimated substantially by the bolometer located far away from the impurity source region. The upstream shift of the radiating zone in case of increasing radiation level is accompanied by a toroidal shift of this zone away from the divertor towards the triangular cross sections. The toroidal deviation between divertor and bolometer plane radiation moderates according to $3 \mathrm{D}$ modeling for total radiative power $f_{\text {rad }} \leq 60 \%$ to less than $10 \%$ (for $\mathrm{Ne}$ ). A migration study of partially-recycling nitrogen is neglected at this point since it is more sophisticated and 
computationally expensive.

These results are very promising and will support thess development of methods for radiative power control and detachment based on an active feedback control systemon 67, 68. These results are in particular promising in view of reliable mitigation of heat fluxes during future long pulse operation and in the absence of intrinsic light impurities when stepping towards a divertor based on reactor relevant materials 21, 22.

\section{Conclusions}

Controlled radiative power exhaust with impurity seeding has been demonstrated in the W7-X island divertor for the first time.

The island divertor configuration allows for stable and ${ }^{100}$ sustained high radiation scenarios with impurity seeding and strongly reduced divertor heat loads in detachment for the price of a loss in energy confinement of $\Delta \tau_{W} \geq-15$ $\%$.

Neon is a very efficient radiator, and short injections allow for significant and sustained enhancement of $P_{\text {rad }}^{1100}$ with a decay time on the order of tens of seconds.

Nitrogen seeding features lower recycling and requires seeding in a continuous mode in order to establish significant enhancement of radiated power and detachment of divertor heat fluxes. $P_{\text {rad }}$ decays within less than a second for short pulses, but for several seconds in case of long and continuous injection. $\mathrm{N}_{2}$ is, therefore, a promising candidate for radiated power control with a feedback system.

Both seeding gases allowed for global control of heat14 fluxes until detachment despite the use of only a single gas source and the $3 \mathrm{D}$ magnetic island flux tube structure in $\mathrm{H}_{16}$ the presented scenarios.

CIS measurements have confirmed the damping of the ${ }^{18}$ counter streaming SOL flows in response to seeding as ${ }_{1120}$ predicted by $3 \mathrm{D}$ modeling. The main SOL flow damping matches with the measured reduction of the downstream 22 particle fluxes estimated by ion saturation currents linked to a reduction of the convective divertor heat fluxes and ${ }^{12}$ the onset of detachment.

Impurity seeding has to be supported by active density control in order to maintain density and neutral pressure. ${ }^{128}$ Divertor gas fueling is a promising technique for density ${ }_{30}$ fine control in support of impurity seeding.

3D modeling confirms and resolves the main effects ${ }^{\mathbf{f}^{32}}$ radiative power exhaust on plasma transport and plasmasurface interactions. It resolves in particular the toroidal asymmetry in the radiated power and thereby explains thes6 miss-match between line emission measured in the divertor region and at toroidal locations far away from the divertor. This toroidal asymmetry reduces in high radiation regimess 40 (e.g. $f_{\text {rad }} \geq 60 \%$ with Ne seeding).

The demonstration of reliable heat flux control with im-1142 purity seeding is very promising concerning future $\operatorname{detach}_{\overline{1}_{44}}$ ment control in high-performance scenarios and future up- grades towards a metal divertor. The results may motivate and inform the development of feedback controlled impurity seeding for machine safety and sustainment of detached operation.

\section{Acknowledgements}

This work was supported in part by the U.S. Department of Energy (DoE) under grant DE-SC0014210 and funding by the Department of Engineering Physics and of the College of Nuclear Engineering at the University of Wisconsin - Madison, USA. The publisher, by accepting the article for publication acknowledges, that the United States Government retains a non-exclusive, paid-up, irrevocable, world-wide license to publish or reproduce the published form of this manuscript, or allow others to do so, for United States Government purposes. This work has been carried out within the framework of the EUROfusion Consortium and has received funding from the Euratom research and training programme 2014-2018 and 2019-2020 under grant agreement No 633053. The views and opinions expressed herein do not necessarily reflect those of the European Commission. The authors thank Dr. Kenneth Hammond and Hannes Damm for their valuable input. This research was performed using the computer resources and assistance of the UW-Madison Center For High Throughput Computing (CHTC) and the high performance computing system Draco of the Max-PlanckSociety at Rechenzentrum Garching (RZG).

\section{References}

[1] W. Fundamenski, R. Pitts, G. Matthews, V. Riccardo, S. Sipil, J. E. Contributors, ELM-averaged power exhaust on JET, Nuclear Fusion 45 (8) (2005) 950-975. doi:10.1088/0029-5515/ 45/8/024

URL https : //doi . org/10.1088\%2F0029-5515\%2F45\%2F8\%2F024

[2] S. Dai, M. Kobayashi, G. Kawamura, S. Morita, H. Zhang, T. Oishi, Y. Feng, D. Wang, Y. Suzuki, the LHD Experimental Group, Emc3-eirene modelling of edge impurity transport in the stochastic layer of the large helical device compared with extreme ultraviolet emission measurements Nuclear Fusion 56 (6) (2016) 066005.

URL http://stacks .iop.org/0029-5515/56/i=6/a=066005

[3] R. König, P. Grigull, K. McCormick, Y. Feng, J. Kisslinger, A. Komori, S. Masuzaki, K. Matsuoka, T. Obiki, N. Ohyabu, H. Renner, F. Sardei, F. Wagner, A. Werner, The divertor program in stellarators Plasma Physics and Controlled Fusion 44 (11) (2002) 2365-2422. doi:10.1088/0741-3335/44/11/306. URL https://doi.org/10.1088\%2F0741-3335\%2F 44\%2F $11 \%$ 2F306

[4] P. C. Stangeby, The Plasma Boundary of Magnetic Fusion Devices, Plasma Physics Series, Nicki Dennis, 2000.

[5] C. Beidler, G. Grieger, F. Herrnegger, E. Harmeyer, J. Kisslinger, W. Lotz, H. Maassberg, P. Merkel, J. Nhrenberg, F. Rau, J. Sapper, F. Sardei, R. Scardovelli, A. Schlter, H. Wobig, Physics and engineering design for wendelstein vii-x, Fusion Technology 17 (1) (1990) 148-168. arXiv:https://doi. org/10.13182/FST90-A29178, doi:10.13182/FST90-A29178 URL https: //doi .org/10.13182/FST90-A29178

[6] G. Grieger, W. Lotz, P. Merkel, J. Nhrenberg, J. Sapper, E. Strumberger, H. Wobig, R. Burhenn, V. Erckmann, U. Gasparino, L. Giannone, H. J. Hartfuss, R. Jaenicke, G. Khner, 
1146 H. Ringler, A. Weller, F. Wagner, the W7X Team, the W7AS Team, Physics optimization of stellarators, Physics of 18 Fluids B 4 (7).

[ [7] R. Wolf, A stellarator reactor based on the optimization criteria 20

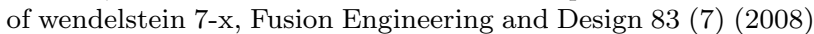
990 - 996, proceedings of the Eight International Symposium of22 Fusion Nuclear Technology. doi:https://doi.org/10.1016/j. fusengdes.2008.05.008

1224 URL http://www.sciencedirect.com/science/article/pii/ S0920379608001063

[8] Y. Feng, F. Sardei, P. Grigull, K. McCormick, J. Kisslinger, D. Reiter, Physics of island divertors as highlighted by the exz 28 ample of w7-as Nuclear Fusion 46 (8) (2006) 807 URL http ://stacks . iop.org/0029-5515/46/i=8/a=006 1230

9] Y. Feng, Up-scaling the island divertor along the w7-stellarator line Journal of Nuclear Materials 438, Supplement (2013ł32 S497 - S500, proceedings of the 20th International Conference on Plasma-Surface Interactions in Controlled Fusion Devices234 doi:http://dx.doi.org/10.1016/j.jnucmat.2013.01.102 URL http://www.sciencedirect.com/science/article/piilk36 S0022311513001104

[10] A. E. al Peacock, A. Peacock, J. Kisslinger, J. Boscaryz38 J. Geiger, F. Hurd, R. Konig, M. Krychowiak, R. Stadler, M. Smirnow, J. Tretter, A. Werner, A proposed scraper elez 10 ment to protect the end of the $\mathrm{w} 7$-x divertor target elements in: A proposed scraper element to protect the end of the W7-1 42 divertor target elements, 2011 IEEE 24th Symposium on Fusion Engineering (SOFE), 2011, pp. 1-5. doi:10.1109/SOFE.20112 14 6052300 URL http://tinyurl.sfx.mpg.de/v12e

[11] J. Geiger, R. C. Wolf, C. Beidler, A. Cardella, E. Chlechowitz, V. Erckmann, G. Gantenbein, D. Hathiramani, M. Hirsch248 W. Kasparek, J. Kilinger, R. Knig, P. Kornejew, H. P. Laqua, C. Lechte, J. Lore, A. Lumsdaine, H. Maaberg, N. B250 Marushchenko, G. Michel, M. Otte, A. Peacock, T. S. Pedersen, M. Thumm, Y. Turkin, A. Werner, D. Zhang, the W7-X Teanns52 Aspects of steady-state operation of the wendelstein 7 -x stellarator, Plasma Physics and Controlled Fusion 55 (1) (2013ł54 014006 .

URL http: //stacks . iop.org/0741-3335/55/i=1/a=014006 1256

[12] J. Lore, Y. Gao, J. Geiger, H. Hoelbe, H. Niemann, M. Jakubowski, G. Wurden, S. Lazerson, P. Drewelow, A. Aliz5s A. P. Sitjes, A. LeViness, H. Frerichs, T. Barbui, F. Effenberg, J. Harris, A. Lumsdaine, J. Boscary, F. Pisano, B. G260 and, Measurement and modeling of magnetic configurations to mimic overload scenarios in the w7-x stellarator, Nuclear Fusianz 59 (6) (2019) 066041. doi:10.1088/1741-4326/ab18d1 URL https ://doi.org/10.1088\%2F1741-4326\%2Fab18d1 1264

[13] U. Samm, G. Bertschinger, P. Bogen, J. D. Hey, E. Hintz, L. Konen, Y. T. Lie, A. Pospieszczyk, D. Rusbulditz66 R. P. Schorn, B. Schweer, M. Tokar, B. Unterberg, Radiative edges under control by impurity fluxes Plasma68 Physics and Controlled Fusion 35 (SB) (1993) B167-B175. doi:10.1088/0741-3335/35/sb/013 URL https://doi.org/10.1088\%2F0741-3335\%2F35\%2Fsb\% $2 \mathrm{~F} 013$

[14] A. Kallenbach, R. Dux, V. Mertens, O. Gruber, G. Haas, M. Kaufmann, W. Poschenrieder, F. Ryter, H. Zohm²4 M. Alexander, K. Behringer, M. Bessenrodt-Weberpals, H.-S. Bosch, K. Buchl, A. Field, J. Fuchs, O. Gehrez76 A. Herrmann, S. Hirsch, W. Koppendorfer, K. Lackner, K. Mast, G. Neu, J. Neuhauser, S. D. P. Hempel, G. Raupp278 K. Schonmann, A. Stabler, K.-H. Steuer, O. Vollmer, M. Weinlich, W. West, T. Zehetbauer, H mode discharges witlz 30 feedback controlled radiative boundary in the ASDEX upgrade tokamak, Nuclear Fusion 35 (10) (1995) 1231-1246282 doi:10.1088/0029-5515/35/10/i07.

URL https://doi.org/10.1088\%2F0029-5515\%2F35\%2F $10 \%$ \% 34 $2 \mathrm{FiO} 7$

[15] G. Matthews, B. Balet, J. Cordey, S. Davies, G. Fishpoalzse H. Guo, L. Horton, M. von Hellermann, L. Ingesson, J. Linger- tat, A. Loarte, G. McCracken, C. Maggi, R. Monk, V. Parail, R. Reichle, M. Stamp, P. Stangeby, D. Stork, A. Taroni, G. Vlases, K.-D. Zastrow, Studies in JET divertors of varied geometry. II: Impurity seeded plasmas, Nuclear Fusion 39 (1) (1999) 19-40. doi:10.1088/0029-5515/39/1/302

URL https : //doi . org/10.1088\%2F0029-5515\%2F39\%2F $\% 2$ F302

[16] J. Rapp, T. Eich, M. von Hellermann, A. Herrmann, L. C. Ingesson, S. Jachmich, G. F. Matthews, V. Philipps, G. Saibene, contributors to the EFDA-JET Workprogramme, ELM mitigation by nitrogen seeding in the JET gas box divertor Plasma Physics and Controlled Fusion 44 (6) (2002) 639-652. doi: 10.1088/0741-3335/44/6/302

URL https : //doi .org/10.1088\%2F0741-3335\%2F44\%2F6\%2F302

[17] S. Brezinsek, T. Loarer, V. Philipps, H. Esser, S. Grnhagen, R. Smith, R. Felton, J. Banks, P. Belo, A. Boboc, J. Bucalossi, M. Clever, J. Coenen, I. Coffey, S. Devaux, D. Douai, M. Freisinger, D. Frigione, M. Groth, A. Huber, J. Hobirk, S. Jachmich, S. Knipe, K. Krieger, U. Kruezi, S. Marsen, G. Matthews, A. Meigs, F. Nave, I. Nunes, R. Neu, J. Roth, M. Stamp, S. Vartanian, U. S. and, Fuel retention studies with the ITER-like wall in JET, Nuclear Fusion 53 (8) (2013) 083023. doi:10.1088/0029-5515/53/8/083023

URL https://doi.org/10.1088\%2F0029-5515\%2F53\%2F8\% 2F083023

[18] R. Pitts, S. Carpentier, F. Escourbiac, T. Hirai, V. Komarov, S. Lisgo, A. Kukushkin, A. Loarte, M. Merola, A. S. Naik, R. Mitteau, M. Sugihara, B. Bazylev, P. Stangeby, A full tungsten divertor for iter: Physics issues and design status Journal of Nuclear Materials 438 (2013) S48 - S56, proceedings of the 20th International Conference on Plasma-Surface Interactions in Controlled Fusion Devices. doi:https://doi.org/10.1016/ j.jnucmat. 2013.01.008

URL http://www.sciencedirect.com/science/article/pii/ S0022311513000160

[19] J. W. Coenen, S. Antusch, M. Aumann, W. Biel, J. Du, J. Engels, S. Heuer, A. Houben, T. Hoeschen, B. Jasper, F. Koch, J. Linke, A. Litnovsky, Y. Mao, R. Neu, G. Pintsuk, J. Riesch, M. Rasinski, J. Reiser, M. Rieth, A. Terra, B. Unterberg, T. Weber, T. Wegener, J.-H. You, C. Linsmeier, Materials for demo and reactor applicationsboundary conditions and new concepts, Physica Scripta 2016 (T167) (2016) 014002.

URL http://stacks.iop.org/1402-4896/2016/i=T167/a= 014002

[20] S. Wiesen, M. Groth, M. Wischmeier, S. Brezinsek, A. Jarvinen, F. Reimold, L. Aho-Mantila, Plasma edge and plasma-wall interaction modelling: Lessons learned from metallic devices, Nuclear Materials and Energy 12 (2017) $3-17$, proceedings of the 22nd International Conference on Plasma Surface Interactions 2016, 22nd PSI. doi:https://doi.org/10.1016/j.nme. 2017.03 .033

URL http://www.sciencedirect.com/science/article/pii/ S2352179116300370

[21] F. Warmer, V. Bykov, M. Drevlak, A. Huler, U. Fischer, T. Stange, C. Beidler, R. Wolf, From w7-x to a helias fusion power plant: On engineering considerations for next-step stellarator devices, Fusion Engineering and Design 123 (2017) 47 - 53, proceedings of the 29th Symposium on Fusion Technology (SOFT-29) Prague, Czech Republic, September 5-9, 2016. doi:https://doi.org/10.1016/j.fusengdes.2017.05.034 URL http://www.sciencedirect.com/science/article/pii/ S0920379617305781

[22] D. Gates, D. Anderson, S. Anderson, M. Zarnstorff, D. Spong, H. Weitzner, G. Neilson, D. Ruzic, D. Andruczyk, J. Harris, H. Mynick, C. Hegna, O. Schmitz, J. Talmadge, D. Curreli, D. Maurer, A. Boozer, S. Knowlton, J. Allain, D. Ennis, G. Wurden, A. Reiman, J. Lore, M. Landreman, J. Freidberg, S. Hudson, M. Porkolab, D. Demers, J. Terry, E. Edlund, S. Lazerson, N. Pablant, R. Fonck, F. Volpe, J. Canik, R. Granetz, A. Ware, J. Hanson, S. Kumar, C. Deng, K. Likin, A. Cerfon, A. Ram, A. Hassam, S. Prager, C. Paz-Soldan, M. Pueschel, I. Joseph, A. Glasser, Stellarator research op- 
portunities: A report of the national stellarator coordinating committee, Journal of Fusion Energy 37 (1) (2018) 51-94360 doi:10.1007/s10894-018-0152-7.

[23] Y. Feng, F. Sardei, J. Kisslinger, P. Grigull, K. McCormick 362 D. Reiter, 3d edge modeling and island divertor physics Contributions to Plasma Physics 44 (1-3) (2004) 57-69. doì334 $10.1002 /$ ctpp. 200410009

URL http://dx.doi.org/10.1002/ctpp. 200410009 lung und Anwendung stochastischer Modelle zur Beschreibung68 des Neutralgastransports, Technical Report Jül-1947.

[25] M. Kobayashi, S. Morita, C. Dong, Z. Cui, Y. Pan, Y. Gaoß70 H. Zhou, Y. Feng, S. Masuzaki, M. Goto, T. Morisaki, H. Yamada, J. Cheng, P. Sun, Q. Yang, X. Duan, the LHD Expers72 iment Group, Edge impurity transport study in the stochastic layer of lhd and the scrape-off layer of hl-2a Nuclear Fusiom 74 53 (3) (2013) 033011.

URL http://stacks . iop. org/0029-5515/53/i=3/a=033011 1376

[26] S. Dai, M. Kobayashi, G. Kawamura, S. Masuzaki, H. Tanaka,

Y. Suzuki, Y. Feng, D. Z. Wang, the LHD Experimental Groupæ378 Investigation of heat flux deposition on divertor target on the large helical device with emc3-eirene modelling Plasma Physics8o and Controlled Fusion 59 (8) (2017) 085013.

URL http://stacks.iop.org/0741-3335/59/i=8/a=085013 1382

[27] T. Oishi, S. Morita, S. Dai, M. Kobayashi, G. Kawamura, X. Huang, H. Zhang, Y. Liu, M. Goto, the LHD Expeniss4 ment Group, Observation of carbon impurity flow in the edge stochastic magnetic field layer of large helical device and its ims 36 pact on the edge impurity control Nuclear Fusion 58 (1) (2018) 016040.

URL http://stacks . iop.org/0029-5515/58/i=1/a=016040

[28] A. Bader, D. Anderson, C. Hegna, Y. Feng, J. Lore, J. Talls9o madge, Simulations of edge configurations in quasi-helically symmetric geometry using emc3eirene, Nuclear Fusion 53 (11\$92 (2013) 113036

URL http://stacks . iop.org/0029-5515/53/i=11/a=113036 1394

[29] A. R. Akerson, A. Bader, C. C. Hegna, O. Schmitz, L. A. Stephey, D. T. Anderson, F. S. B. Anderson, K. M. Likinz96 Three-dimensional scrape off layer transport in the helically symmetric experiment HSX Plasma Physics and Controlled Fus98 sion 58 (8) (2016) 084002 .

URL http://stacks . iop.org/0741-3335/58/i=8/a=084002 1400

[30] S. Marcinko, D. Curreli, Numerical characterization of the edge transport conditions and limiter fluxes of the hidra stellarator 402 Physics of Plasmas 25 (2) (2018) 022507. arXiv:https://doi. org/10.1063/1.5018215 doi:10.1063/1.5018215

URL https://doi.org/10.1063/1.5018215

[31] Y. Feng, F. Sardei, P. Grigull, K. McCormick, J. Kisslingerło D. Reiter, Y. Igitkhanov, Transport in island divertors: physics, 3d modelling and comparison to first experiments on w7-ASł 08 Plasma Physics and Controlled Fusion 44 (5) (2002) 611-625. doi: $10.1088 / 0741-3335 / 44 / 5 / 308$ URL https://doi .org/10.1088\%2F0741-3335\%2F44\%2F5\%2F308

[32] Y. Feng, T. Lunt, F. Sardei, X. Zha, Implicit coupling of ima12 purity transport at the SOL-core interface, Computer Physics Communications 184 (6) (2013) 1555 - 1561. doi:http://dx414 doi.org/10.1016/j.cpc.2013.02.003

URL http://wwW.sciencedirect.com/science/article/piii/16 S0010465513000477

[33] Y. Feng, C. Beidler, J. Geiger, P. Helander, H. Hlbe, H. Maass418 berg, Y. Turkin, D. Reiter, W.-X. Team, On the w7-x divertor performance under detached conditions Nuclear Fusion $56(12420$ (2016) 126011.

URL http://stacks . iop.org/0029-5515/56/i=12/a=126011 1422

[34] F. Effenberg, Y. Feng, O. Schmitz, H. Frerichs, S. Bozhenkov, H. Hlbe, R. Knig, M. Krychowiak, T. S. Pedersen, D. Reiter424 L. Stephey, W.-X. Team, Numerical investigation of plasma edge transport and limiter heat fluxes in wendelstein 7-x startup 26 plasmas with emc3-eirene Nuclear Fusion 57 (3) (2017) 036021. URL http://stacks . iop. org/0029-5515/57/i=3/a=036021 1428 [35] G. Wurden, C. Biedermann, F. Effenberg, M. Jakubowski,
H. Niemann, L. Stephey, S. Bozhenkov, S. Brezinsek, J. Fellinger, B. Cannas, F. Pisano, S. Marsen, H. Laqua, R. Knig, O. Schmitz, J. Harris, E. Unterberg, the W7-X Team, Limiter observations during w7-x first plasmas, Nuclear Fusion 57 (5) (2017) 056036

URL http://stacks . iop.org/0029-5515/57/i=5/a=056036

[36] V. R. Winters, S. Brezinsek, F. Effenberg, M. Rasinski, O. Schmitz, L. Stephey, C. Biedermann, C. P. Dhard, H. Frerichs, J. Harris, M. Krychowiak, R. Knig, T. S. Pedersen, G. A. Wurden, the W7-X team, Overview of the plasma-surface interaction on limiter surfaces in the startup campaign of wendelstein 7-x Physica Scripta 2017 (T170) (2017) 014050. URL http://stacks.iop.org/1402-4896/2017/i=T170/a= 014050

37] L. Stephey, A. Bader, F. Effenberg, O. Schmitz, G. A. Wurden, D. T. Anderson, F. S. B. Anderson, C. Biedermann, A. Dinklage, Y. Feng, H. Frerichs, G. Fuchert, J. Geiger, J. H. Harris, R. Knig, P. Kornejew, M. Krychowiak, J. D. Lore, E. A. Unterberg, I. Waters, Impact of magnetic islands in the plasma edge on particle fueling and exhaust in the hsx and w7-x stellarators Physics of Plasmas 25 (6) (2018) 062501. arXiv:https: //doi.org/10.1063/1.5026324 doi:10.1063/1.5026324 URL https://doi .org/10.1063/1.5026324

38] T. S. Pedersen, R. Knig, M. Krychowiak, M. Jakubowski, J. Baldzuhn, S. Bozhenkov, G. Fuchert, A. Langenberg, H. Niemann, D. Zhang, K. Rahbarnia, H.-S. Bosch, Y. Kazakov, S. Brezinsek, Y. Gao, N. Pablant, the W7-X Team, First results from divertor operation in wendelstein 7-x Plasma Physics and Controlled Fusion 61 (1) (2019) 014035. URL http://stacks . iop.org/0741-3335/61/i=1/a=014035

[39] F. Effenberg, H. Niemann, Y. Feng, J. Geiger, O. Schmitz, Y. Suzuki, A. Ali, T. Barbui, S. Brezinsek, H. Frerichs, M. Jakubowski, R. Knig, M. Krychowiak, A. P. Sitjes, J. Schmitt, T. S. Pedersen, Investigation of 3d effects on heat fluxes in performance-optimized island divertor configurations at wendelstein 7-x, Nuclear Materials and Energy 18 (2019) 262 - 267. doi:https://doi.org/10.1016/j.nme.2019.01.006 URL http://www.sciencedirect.com/science/article/pii/ S2352179118302394

[40] J. Geiger, C. D. Beidler, Y. Feng, H. Maaberg, N. B. Marushchenko, Y. Turkin, Physics in the magnetic configuration space of w7-x, Plasma Physics and Controlled Fusion 57 (1) (2015) 014004.

URL http://stacks . iop.org/0741-3335/57/i=1/a=014004

[41] M. Krychowiak, M. Brix, D. Dodt, Y. Feng, R. Knig, O. Schmitz, J. Svensson, R. Wolf, Bayesian modelling of a thermal helium beam for measurement of electron density and temperature in the w7-x divertor plasma Plasma Physics and Controlled Fusion 53 (3) (2011) 035019. doi:10.1088/0741-3335/53/3/035019

URL https://doi.org/10.1088\%2F0741-3335\%2F53\%2F3\% 2F035019

[42] T. Barbui, M. Krychowiak, R. Knig, O. Schmitz, J. M. M. Burgos, B. Schweer, A. Terra, W.-X. Team, Feasibility of line-ratio spectroscopy on helium and neon as edge diagnostic tool for wendelstein $7-\mathrm{x}$, Review of Scientific Instruments 87 (11) (2016) 11E554. arXiv: https://aip.scitation.org/doi/pdf/10.1063/1.4962989 doi:10.1063/1.4962989

URL https://aip.scitation.org/doi/abs/10.1063/1. 4962989

[43] R. Laube, M. Laux, M. Y. Ye, H. Greuner, S. Lindig, Designs of langmuir probes for w7-x Fusion Engineering and Design 86 (6) (2011) 1133 - 1136, proceedings of the 26th Symposium of Fusion Technology (SOFT-26). doi:https://doi.org/10.1016/ j.fusengdes.2010.12.059

URL http://www.sciencedirect.com/science/article/pii/ S0920379610006046

[44] D. Zhang, R. Burhenn, R. Koenig, L. Giannone, P. A. Grodzki, B. Klein, K. Grosser, J. Baldzuhn, K. Ewert, V. Erckmann, M. Hirsch, H. P. Laqua, J. W. Oosterbeek, Design criteria of 
1430 the bolometer diagnostic for steady-state operation of the w7X stellarator, Review of Scientific Instruments 81 (10) (2010) 02 10E134. arXiv:https://doi.org/10.1063/1.3483194 doi:10. 1063/1.3483194 URL https ://doi .org/10.1063/1.3483194

[45] M. Jakubowski, P. Drewelow, J. Fellinger, A. Puig Sitjeşo6 G. Wurden, A. Ali, C. Biedermann, B. Cannas, D. Chauvin, M. Gamradt, H. Greve, Y. Gao, D. Hathiramani, R. Knigsos A. Lorenz, V. Moncada, H. Niemann, T. T. Ngo, F. Pisano, T. Sunn Pedersen, Infrared imaging systems for wall protec5 10 tion in the w7-x stellarator (invited), Review of Scientific Instruments 89 (10) (2018) 10E116. arXiv:https://doi.org/10512 1063/1.5038634 doi:10.1063/1.5038634 URL https://doi.org/10.1063/1.5038634

[46] Y. Gao, M Jakubowski, P. Drewelow, F Pisano, A. P. Sitjes, H. Niemann, A. Ali, B. Cannas, Methods for quantitative studys 16 of divertor heat loads on w7-x, Nuclear Fusion. URL http://iopscience.iop.org/10.1088/1741-4326/ab0f4918

[47] V. Perseo, R. König, C. Biedermann, O. Ford, D. Gradic, M. Krychowiak, G. Kocsis, D. Ennis, D. Maurer, T. S. Peds20 ersen, W.-X. Team, Coherence Imaging Spectroscopy systems on Wendelstein 7-X for studies of island divertor plasma behav5 22 ior 44th EPS Conference on Plasma Physics.

URL http://ocs.ciemat.es/EPS2017PAP/pdf/P5.103.pdf 1524

[48] D. Gradic, O. P. Ford, A. Burckhart, F. Effenberg, H. Frerichs, R. Knig, T. Lunt, V. Perseo, R. C. Wolf, A. U. Team, W. .-X526 Team, E. M. team, Doppler coherence imaging of divertor and sol flows in asdex upgrade and wendelstein 7-x, Plasma Physics 28 and Controlled Fusion 60 (8) (2018) 084007. URL http://stacks . iop.org/0741-3335/60/i=8/a=084007 1530

[49] V. Perseo, F. Effenberg, D. Gradic, R. Koenig, O. Ford, D. Ennis, O. Schmitz, T. S. Pedersen, W.-X. Team, Direct measuress2 ments of counter-streaming flows in a stellarator magnetic island topology (submitted 2019).

[50] W. Biel, G. Bertschinger, R. Burhenn, R. Knig, E. Jourdain, Design of a highefficiency extreme ultraviolet overview spec5 36 trometer system for plasma impurity studies on the stellarator experiment wendelstein 7-x Review of Scientific Instruments 38 75 (10) (2004) 3268-3275. arXiv:https://doi.org/10.1063/ 1.1784557, doi:10.1063/1.1784557

URL https://doi.org/10.1063/1.1784557

[51] U. Wenzel, T. Kremeyer, G. Schlisio, M. Marquardt, T. Ped542 ersen, O. Schmitz, B. Mackie, J. M.-B. and, Advanced neutral gas diagnostics for magnetic confinement devices; 44 Journal of Instrumentation 12 (09) (2017) C09008-C09008. doi:10.1088/1748-0221/12/09/c09008

URL 2Fc09008

https://doi.org/10.1088\%2F $1748-0221 \% 2 \mathrm{~F} 12 \% 2 \mathrm{~F} 09 \%$

D. Hathiramani, A. Ali, G. Anda, T. Barbui, C. Biedermann, A. Charl, D. Chauvin, G. Czymek, C. Dhard, P. Drewelow550 A. Dudek, F. Effenberg, G. Ehrke, M. Endler, D. Ennis, J. Fellinger, O. Ford, S. Freundt, D. Gradic, K. Grosser, J. Harss2 ris, H. Hlbe, M. Jakubowski, M. Knaup, G. Kocsis, R. Knig, M. Krause, T. Kremeyer, P. Kornejew, M. Krychowiak, H. Lann554 bertz, H. Jenzsch, M. Mayer, S. Mohr, O. Neubauer, M. Otte, V. Perseo, D. Pilopp, L. Rudischhauser, O. Schmitz, B. Schweers56 M. Schlke, L. Stephey, T. Szepesi, A. Terra, M. Toth, U. Wenzel, G. Wurden, S. Zoletnik, T. S. Pedersen, Upgrades of edgess 8 divertor and scrape-off layer diagnostics of w7x for op1.2, Fusion Engineering and Design 136 (2018) 304 - 308, special Issues60 Proceedings of the 13th International Symposium on Fusion Nuclear Technology (ISFNT-13). doi:https://doi.org/10.1016t/32 j.fusengdes.2018.02.013

URL http://www.sciencedirect.com/science/article/piilf 34 S0920379618301108

[53] A. Kallenbach, M. Bernert, R. Dux, L. Casali, T. Eichs66 L. Giannone, A. Herrmann, R. McDermott, A. Mlynek, H. W. Mller, F. Reimold, J. Schweinzer, M. Sertoli, G. Tardinis68 W. Treutterer, E. Viezzer, R. Wenninger, M. W. and, Impurity seeding for tokamak power exhaust: from present devices via 70 ITER to DEMO Plasma Physics and Controlled Fusion 55 (12)
(2013) 124041. doi:10.1088/0741-3335/55/12/124041

URL https://doi.org/10.1088\%2F0741-3335\%2F55\%2F $12 \%$ 2F124041

[54] T. Morisaki, K. Oyama, N. Tamura, S. Masuzaki, T. Akiyama, G. Motojima, J. Miyazawa, B. Peterson, N. Ohno, H. Yamada, Radiated power distributions in impurity-seeded plasmas in LHD Journal of Nuclear Materials 463 (2015) 640 - 643, 21Proceedings of the 21st International Conference on PlasmaSurface Interactions in Controlled Fusion Devices Kanazawa, Japan May 26-30, 2014. doi:http://dx.doi.org/10.1016/j. jnucmat.2015.01.016

URL http://www.sciencedirect.com/science/article/pii/ S0022311515000203

[55] T. Barbui, F. Effenberg, R. König, M. Krychowiak, O. Schmitz, J. Baldzuhn, B. Blackwell, B. Buttenschön, P. Drews, M. Jakubowski, S. Kwak, Y. Liang, S. Liu, H. Niemann, T. S. Pedersen, J. Svensson, D. Z. and, Radiative edge cooling experiments in wendelstein 7-x start-up limiter campaign, Nuclear Fusion 59 (7) (2019) 076008. doi:10.1088/1741-4326/ab18c5. URL https : //doi .org/10.1088\%2F1741-4326\%2Fab18c5

56] Y. Feng, H. Frerichs, M. Kobayashi, A. Bader, F. Effenberg, D. Harting, H. Hoelbe, J. Huang, G. Kawamura, J. D. Lore, T. Lunt, D. Reiter, O. Schmitz, D. Sharma, Recent improvements in the emc3-eirene code, Contributions to Plasma Physics 54 (4-6) (2014) 426-431. doi:10.1002/ctpp. 201410092 URL http://dx.doi.org/10.1002/ctpp.201410092

[57] D. Reiter, M. Baelmans, P. Börner, The eirene and b2-eirene codes, Fusion Science and Technology 47 (2) (2005) 172-186. arXiv:https://doi.org/10.13182/FST47-172 doi:10.13182/ FST47-172

URL https : //doi .org/10.13182/FST47-172

[58] H. P. Summers, Atomic data and analysis structure: user manual, Joint European Torus, Abingdon, 1994. URL https : //cds . cern . ch/record/277307

59] H. Frerichs, F. Effenberg, O. Schmitz, C. Biedermann, Y. Feng, M. Jakubowski, R. Knig, M. Krychowiak, J. Lore, H. Niemann, T. S. Pedersen, L. Stephey, G. A. Wurden, Synthetic plasma edge diagnostics for emc3-eirene, highlighted for wendelstein 7-x Review of Scientific Instruments 87 (11) (2016) 11D441. arXiv:http://aip.scitation.org/doi/pdf/10.1063/ 1.4959910 doi:10.1063/1.4959910

URL http://aip.scitation.org/doi/abs/10.1063/1.4959910

[60] M. Kubkowska, A. Czarnecka, T. Fornal, M. Gruca, S. Jaboski, N. Krawczyk, L. Ry, R. Burhenn, B. Buttenschn, B. Geiger, O. Grulke, A. Langenberg, O. Marchuk, K. J. McCarthy, U. Neuner, D. Nicolai, N. Pablant, B. Schweer, H. Thomsen, T. Wegner, P. Drews, K.-P. Hollfeld, C. Killer, T. Krings, G. Offermanns, G. Satheeswaran, F. Kunkel, Plasma impurities observed by a pulse height analysis diagnostic during the divertor campaign of the wendelstein 7 -x stellarator Review of Scientific Instruments 89 (10) (2018) 10F111. arXiv:https: //doi.org/10.1063/1.5038850 doi:10.1063/1.5038850 URL https://doi .org/10.1063/1.5038850

[61] D. Zhang, R. König, e. a. Feng, First observation of a stable highly-dissipative divertor plasma regime on the Wendelstein W7-X stellarator (submitted to PRL 2019).

[62] M. Krychowiak, A. Adnan, A. Alonso, T. Andreeva, J. Baldzuhn, T. Barbui, M. Beurskens, W. Biel, C. Biedermann, B. D. Blackwell, H. S. Bosch, S. Bozhenkov, R. Brakel, T. Bruer, B. Brotas de Carvalho, R. Burhenn, B. Buttenschn, A. Cappa, G. Cseh, A. Czarnecka, A. Dinklage, P. Drews, A. Dzikowicka, F. Effenberg, M. Endler, V. Erckmann, T. Estrada, O. Ford, T. Fornal, H. Frerichs, G. Fuchert, J. Geiger, O. Grulke, J. H. Harris, H. J. Hartfu, D. Hartmann, D. Hathiramani, M. Hirsch, U. Hfel, S. Jaboski, M. W. Jakubowski, J. Kaczmarczyk, T. Klinger, S. Klose, J. Knauer, G. Kocsis, R. Knig, P. Kornejew, A. Krmer-Flecken, N. Krawczyk, T. Kremeyer, I. Ksiek, M. Kubkowska, A. Langenberg, H. P. Laqua, M. Laux, S. Lazerson, Y. Liang, S. C. Liu, A. Lorenz, A. O. Marchuk, S. Marsen, V. Moncada, D. Naujoks, H. Neilson, O. Neubauer, U. Neuner, H. Niemann, J. W. Oosterbeek, M. Otte, N. Pablant, 
E. Pasch, T. Sunn Pedersen, F. Pisano, K. Rahbarnia, L. Ry, O. Schmitz, S. Schmuck, W. Schneider, T. Schrder, H. Schuhmacher, B. Schweer, B. Standley, T. Stange, L. Stephey, J. Svensson, T. Szabolics, T. Szepesi, H. Thomsen, J.-M. Travere, H. Trimino Mora, H. Tsuchiya, G. M. Weir, U. Wenzel, A. Werner, B. Wiegel, T. Windisch, R. Wolf, G. A. Wurden, D. Zhang, A. Zimbal, S. Zoletnik, W.-X. Team, Overview of diagnostic performance and results for the first operation phase in wendelstein 7-x (invited), Review of Scientific Instruments 87 (11).

[63] Y. Feng, G. Herre, P. Grigull, F. S. and, The effects of field reversal on the w7-AS island divertor at low densities Plasma Physics and Controlled Fusion 40 (3) (1998) 371-380. doi: 10.1088/0741-3335/40/3/003

URL https : //doi .org/10.1088\%2F0741-3335\%2F40\%2F3\%2F003

[64] S. Bozhenkov, M. Otte, C. Biedermann, M. Jakubowski, S. Lazerson, T. S. Pedersen, R. Wolf, W.-X. Team, Measurements and \begin{tabular}{|l|l|l|}
\hline correction of the $1 / 1$ error field in wendelstein $7-x$ & Nuclear Fu-
\end{tabular} sion 59 (2) (2019) 026004.

URL http://stacks . iop.org/0029-5515/59/i=2/a=026004

[65] S. A. Lazerson, S. Bozhenkov, B. Israeli, M. Otte, H. Niemann, V. Bykov, M. Endler, T. Andreeva, A. Ali, P. Drewelow, M. Jakubowski, A. P. Sitjes, F. Pisano, B. C. and, Error fields in

the wendelstein 7-x stellarator, Plasma Physics and Controlled Fusion 60 (12) (2018) 124002. doi:10.1088/1361-6587/aae96b URL https://doi.org/10.1088\%2F1361-6587\%2Faae96b

[66] T. Barbui, F. Effenberg, M. Jakubowski, R. König, M. Krychowiak, S. Loch, J. Munos Burgos, O. Schmitz, M. P. S. W7-X Team, Max Planck Institute for Plasma Physics, The $\mathrm{He} / \mathrm{Ne}$ beam diagnostic for active emission spectroscopy in the island divertor of Wendelstein 7-X (2018).

[67] A. Kallenbach, M. Bernert, T. Eich, J. Fuchs, L. Giannone, A. Herrmann, J. Schweinzer, W. T. and, Optimized tokamak power exhaust with double radiative feedback in ASDEX upgrade Nuclear Fusion 52 (12) (2012) 122003. doi: $10.1088 / 0029-5515 / 52 / 12 / 122003$.

URL https://doi.org/10.1088\%2F0029-5515\%2F52\%2F $12 \%$ 2F122003

[68] C. Guillemaut, M. Lennholm, J. Harrison, I. Carvalho, D. Valcarcel, R. Felton, S. Griph, C. Hogben, R. Lucock, G. F. Matthews, C. P. V. Thun, R. A. Pitts, S. W. and, Realtime control of divertor detachment in h-mode with impurity seeding using langmuir probe feedback in JET-ITER-like wall Plasma Physics and Controlled Fusion 59 (4) (2017) 045001. doi:10.1088/1361-6587/aa5951 URL https://doi.org/10.1088\%2F1361-6587\%2Faa5951

[69] G. Maddison, C. Giroud, G. McCormick, J. Alonso, B. Alper, G. Arnoux, P. da Silva Aresta Belo, M. Beurskens, A. Boboc, S. Brezinsek, I. Coffey, S. Devaux, T. Eich, W. Fundamenski, D. Harting, A. Huber, S. Jachmich, I. Jenkins, E. Joffrin, M. Kempenaars, M. Lehnen, T. Loarer, P. Lomas, A. Meigs, P. Morgan, V. Riccardo, F. Rimini, M. Stamp, G. Telesca, H. Thomsen, J. E. contributors, Moderation of divertor heat loads by fuelling and impurity seeding in well-confined ELMy H-mode plasmas on JET Nuclear Fusion 51 (4) (2011) 042001. URL http://stacks . iop.org/0029-5515/51/i=4/a=042001

[70] H. Tanaka, G. Kawamura, S. Masuzaki, M. Kobayashi, T. Akiyama, B. Peterson, K. Mukai, R. Sano, S. Dai, R. Sakamoto, T. Morisaki, N. Ohno, Toroidally symmetric/asymmetric effect on the divertor flux due to neon/nitrogen seeding in lhd Nuclear Materials and Energy 12 (2017) 241 - 246, proceedings of the 22nd International Conference on Plasma Surface Interactions 2016, 22nd PSI. doi:https://doi. org $/ 10.1016 / \mathrm{j} . \mathrm{nme} \cdot 2016.12 .020$

URL http://www.sciencedirect.com/science/article/pii/ S2352179116300849 